\title{
INGENIEROS, ARQUITECTOS, MÉDICOS Y LOCURA. LA CONSTRUCCIÓN DEL ASILO COLONIA DE LA MAGDALENA [1896-1918] ${ }^{\left[{ }^{*}\right.}$
}

\author{
ENGINEERS, ARCHITECTS, DOCTORS AND MADNESS. \\ THE CONSTRUCTION OF THE COLONIA DE LA MAGDALENA ASYLUM [1896-1918] \\ ELÍAS AMAYA NÚÑEZ $Z^{(*)}$ \\ Centro de Historia UNI, Universidad Nacional de Ingeniería (Perú) \\ eliasamayanu@gmail.com \\ Fecha de recepción: 03 de abril de 2018 \\ Fecha de aprobación: 14 de junio de 2018
}

\begin{abstract}
RESUMEN
El presente artículo aborda el proceso de configuración y construcción del primer hospital psiquiátrico moderno del Perú. Se centra en las acciones ejercidas por los médicos, ingenieros y arquitectos que participaron en dicho proyecto. El periodo de estudio abarca desde 1896, cuando el Ministerio de Fomento convocó a un concurso para la edificación de una Casa de Insanos que reemplace al Manicomio del Cercado, y finaliza en 1918, con la inauguración del Asilo Colonia de la Magdalena u Hospital Víctor Larco Herrera. El artículo está dividido en dos partes. En la primera sección se describe la importancia que tuvo el profesional técnico y médico en el proceso de modernización de fines del siglo XIX e inicios del XX. Además, se describe el rol desempeñado por el Ministerio de Fomento y la Sociedad de Beneficencia de Lima en ese proceso. Por último, se señalan las características del proyecto ganador del concurso anteriormente mencionado. En la segunda sección se analiza el proceso de construcción del Manicomio General, prestando atención al diálogo entre los agentes participantes (ingenieros, arquitectos y médicos).
\end{abstract}

\section{PALABRAS CLAVE}

Manicomio General, construcción, élites modernizadoras

\section{ABSTRACT}

The following article addresses the configuration and construction of the first modern psychiatric hospital of Peru. It focuses on the actions executed by the doctors, engineers and architects who participated in this project. The study period begins in 1896, when the Ministry of Development called for a public tender in order to receive the best proposals for the construction of a House of the Insane that could replace the Cercado Asylum; it ends in 1918 with the inauguration of Colonia de la Magdalena Asylum or Victor Larco Herrera Hospital. The article is divided into two parts. The first section describes the importance of the technical and medical professionals in the modernization process of the late nineteenth and early twentieth centuries. Furthermore, it describes the role played by the Ministry of Development and the Public Charity Society of Lima in said process. Finally, the characteristics of project that won the above-mentioned tender are shown. In the second section, the article analyzes the construction process of the General Asylum, paying attention to the dialogue that takes place between the participating agents (engineers, architects and doctors).

\section{KEYWORDS}

General Asylum, building, modernizing elites

(*)El presente artículo es una síntesis del libro Médicos, ingenieros y Arquitectos en la Construcción del Asilo Colonia de la Magdalena (1884-conb), realizado en el marco de trabajo del Centro de Historia UNI (Universidad Nacional de Ingeniería) y próximo a publicarse por la editorial de la misma universidad. Se agradece al Dr. José Ignacio López Soria, director del Centro de Historia UNI, por la asesoría brindada a lo largo de la elaboración del libro y del artículo. (**) Bachiller en Historia por la Universidad Nacional Mayor de San Marcos. Investigador del Centro de Historia UNI, espacio en el que actualmente investiga sobre la historia de las energías renovables, específicamente la energía solar. Actualmente se encuentra culminando la tesis de licenciatura en Historia titulada Manuel Antonio Muñiz y la Reforma Psiquiátrica de finales del siglo XIX. 
devenir Vol. 5, Nº10, JULIO - DICIEMBRE 2018, PP. 65-90 - EstudIOS I ISSN 2312-7562 | E-ISSN 2616-4949

UNIVERSIDAD NACIONAL DE INGENIERÍ, LIMA

DOI: https://doi.org/10.21754/devenir.v5i10.599

\section{Modernización, actores e instituciones}

En los siguientes apartados se analiza el contexto, las instituciones y actores que tomaron parte en las obras de construcción de Asilo Colonia de la Magdalena. Así mismo, se describe los componentes generales del proyecto de la Casa de Insanos diseñado por el médico Manuel Antonio Muñiz.

\section{El proceso de modernización y las élites modernizadoras}

En 1896, el regreso al poder de los civilistas, en coalición con Nicolás de Piérola, trajo a Perú una estabilidad política que desde los estragos de la Guerra con Chile era ajena a la realidad nacional. La estabilidad, sumada al crecimiento económico favorecido por la exportación de variedad de productos agrícolas y minerales, permitió a la élite dirigente retomar y replantear el proyecto de modernidad iniciado en la segunda mitad del siglo XIX e interrumpido desde $1879^{1}$. Como era de esperarse, el proyecto de modernidad peruano estuvo inspirado en el proyecto occidental formulado por los ilustrados del siglo XVIII, que consistía esencialmente en un nuevo ordenamiento del mundo sobre la base de un proceso de racionalización de saberes ${ }^{2}$ que no respondía a dogmas o autoridades, sino a su propia lógica (Casullo, Forster \& Kaufman, 2009), una razón con pretensiones de exactitud y animadversión por lo que consideraba desorden (Ruiz, 1994). Estos ideales fueron asumidos y llevados a la realidad peruana por un conjunto de profesionales liberales catalogados por algunos autores como "élites modernizadoras". Integradas por "aquellos individuos que ocupa[ban] posiciones definidas de autoridad a la cabeza de alguna organización o institución" (Muñoz, 2001, pp. 25-26), ya sean públicas o privadas, tenían como propósito "romper con las antiguas formas de organización social política, cultural y económica del país" y construir en su lugar una "nación racionalmente organizada" (Garfias, 2009, p. 156).

Como era de esperarse, estas élites modernizadoras, aunque unidas por una idea en común, tenían distintas formas de interpretar la realidad y, por ende, de buscar su modernización. Estas diferencias quedaron plasmadas en sus discursos. Como señala José Ignacio López Soria (2001), la experiencia de la modernidad en el Perú se puede plasmar en dos discursos. El primero, denominado discurso de las libertades, buscaba crear una sociedad en donde predominara "el desarrollo pleno de la justicia y la libertad" que diera paso al despliegue de las "posibilidades humanas" (2001, pp. 47-57). Al ser sus portadores hombres de letras y juristas, la palabra tenía primacía sobre la obra.

Por otro lado, el discurso del bienestar "es portador de una racionalidad que se orienta a propiciar el desarrollo nacional por la vía de la exploración y la explotación de los recursos naturales y de su incorporación al circuito internacional de la mercancía" (López Soria, 2001, pp. 47-57). También se empeñaban en articular y dominar el territorio nacional, reordenar la ciudad bajo parámetros racionales, instaurar un "lenguaje universal", mejorar el bienestar social de la población, etc. Este discurso se respaldó en la ciencia y la tecnología, y logró su legitimación profesional y social mediante la obra útil (López Soria, 2001; López \& Ludeña, 2000) Los mayores representantes de este discurso fueron los ingenieros, arquitectos y médicos.

\footnotetext{
1. No se aborda aquí el debate sobre si el inicio de la Modernidad debe situarse en la época de los "descubrimientos", conquistas y colonizaciones, o en el Siglo de las Luces. La modernidad a la que aquí nos referimos está relacionada con la racionalización, y las aplicaciones social e individualmente útiles de los conocimientos científicos.

2. Según Habermas (2002), estos saberes fueron una ciencia objetiva, una moralidad y leyes universales, y un arte autónomo acorde con una lógica interna.
} 
La influencia del positivismo ${ }^{3}$ y su fe en el progreso y en la ciencia marcaron la dirección que tomaron las acciones de la élite dirigente. Prestando mayor atención al desarrollo de la ciencia y la tecnología, el Estado, como impulsor de la modernización nacional, favoreció los espacios donde esos conocimientos se producían e impartían. No es raro que en este proceso, por el énfasis puesto en el desarrollo material, la universidad fuese de alguna manera dejada de lado para apostar por la enseñanza técnica y científica que se impartía en las escuelas técnicas y de medicina, pues "estaban más conectadas a la transformación material, al incremento del aparato productivo y, en general, al crecimiento de la riqueza del país" (Garfias, 2009, p. 151). En consecuencia, la Escuela de Ingenieros, la Escuela de Agricultura, la Escuela de Artes y Oficios, y la Facultad de Medicina de San Marcos concentraron tanto la atención como los fondos de la élite dirigente a finales del siglo XIX e inicios del siglo XX (Garfias, 2009).

\section{El Ministerio de Fomento y el progreso material}

Al otorgamiento de incentivos al medio educativo técnico le siguió la creación de una serie de instituciones públicas cuya finalidad era mejorar el aparato fiscal y administrativo del Estado. Entre este amplio grupo de entidades destacó el Ministerio de Fomento, inaugurado en 1896.

La creación de este nuevo ministerio significó un punto de inflexión respecto del orden administrativo anterior a la Guerra con Chile. A finales del siglo XIX, una serie de factores confluyeron (la estabilidad política, el crecimiento económico y las élites modernizadoras) con la "experiencia histórica" del Estado peruano, lo que llevó a "constituir un espacio donde las obras de modernización pudiesen diseñarse y supervisarse de manera más organizada y profesional" (Quiñones, 2014, p. 8).

Para llevar a cabo ese objetivo, el Ministerio estuvo en un inicio integrado por tres dependencias que canalizaron sus actividades en distintas direcciones: Obras Públicas, Industria y Beneficencia. Con esta distribución se intentó encaminar realidad social hacia la modernidad. Como señala Leticia Quiñones (2014), el Ministerio de Fomento tuvo como objetivo el desarrollo de infraestructura, el impulso de las actividades económicas y el desarrollo social. No obstante, para enfrentar esos enormes desafíos era necesario contar con un adecuado cuerpo profesional.

Como se señaló anteriormente, la apuesta por las escuelas técnicas tuvo como objetivo formar profesionales útiles a los fines modernizadores de la élite política. Por ello, para que el Ministerio de Fomento pudiera materializar sus políticas de Estado, era necesario que se sirviera de esas canteras técnicas. La Escuela de Ingenieros, desde su fundación en 1876, se había ocupado de proporcionar al Estado un cuerpo profesional preparado para trabajar en diversas áreas: construcción civil, minería y agrimensura. Posteriormente, el desarrollo industrial y urbano de inicios del siglo XX obligó a la creación de nuevas secciones, como ingeniería industrial, de electricistas y de arquitectos constructores (López Soria, 2003). Por su parte, el Ministerio de Fomento se sirvió del Cuerpo de Ingenieros de Minas (1920) y del Cuerpo de Ingenieros de Caminos (1905) (Quiñones, 2014).

Entre el conjunto de los profesionales que integraban la plana de funcionarios del $\mathrm{Mi}-$ nisterio de Fomento, sobresalieron los vinculados a la ingeniería, la arquitectura y la medicina. Este cuerpo de profesionales técnicos o élites modernizadoras, imbuido del discurso del bienestar, iba a comandar, a través de las distintas secciones del Ministerio de Fomento, el desarrollo material y social del país (Quiñones, 2014).

3. Para el estudio del positivismo, ver Salazar Bondy (1967) y Sobrevilla (1980). Para un balance historiográfico del caso peruano, consultar Paul Montoya (2003). 
devenir Vol. 5, Nº10, JULIO - DICIEMBRE 2018, PP. 65-90 - EstudIOS I ISSN 2312-7562 | E-ISSN 2616-4949

UNIVERSIDAD NACIONAL DE INGENIERÍA, LIMA

DOI: https://doi.org/10.21754/devenir.v5i10.599

Como se mencionó anteriormente, al ser una de las prioridades del Ministerio de Fomento el desarrollo social, las Sociedades Públicas de Beneficencia de todo el país pasaron a ser integradas a una de sus secciones. En el siguiente apartado se desarrollará el caso de la Sociedad de Beneficencia de Lima.

\section{La Sociedad de Beneficencia Pública de Lima y el Manicomio General}

La Sociedad de Beneficencia de Lima, en su misión de proteger y asistir a la población más menesterosa de la ciudad, supo concentrar la caridad pública de las familias más importantes del país, es decir las más "respetadas" y acaudaladas. Los requisitos, un tanto elitistas, para ser miembro de esta Sociedad, eran de carácter moral y económico ${ }^{4}$. En general, resultaba atractivo para estas familias ser miembros de la Sociedad por el prestigio y el reforzamiento del status que de ello se derivaban. A pesar de ser una institución pública y depender directamente del Estado, por medio de la Dirección de Fomento del Ministerio de Fomento, la Sociedad gozaba de la atribución de adquirir y administrar sus propios bienes, los cuales provenían principalmente de las herencias y donaciones hechas por sus socios o filántropos (García, 2004). A simple vista esta facultad podría parecer beneficiosa, pero a largo plazo le traería serios problemas económicos.

Al recaer en la Sociedad de Beneficencia de Lima la administración y mantenimiento de los establecimientos hospitalarios de la capital (hospitales, asilos, casas de cuna, etc.), esta entidad tuvo que hacer frente a los gastos de personal, mantenimiento y provisión. Para ello se sirvió inicialmente de los ingresos obtenidos por las rentas de las propiedades donadas, el ramo de suertes (loterías) ${ }^{5}$ y las dádivas de sus socios. ${ }^{6}$

A pesar de los artificios usados por la Sociedad de Beneficencia para cubrir los gastos de las dependencias a su cargo, la mayoría del tiempo, como se puede constatar en las memorias de sus directores, la institución presentaba problemas económicos. Los estragos materiales provocados por la Guerra con Chile marcaron el estado de los establecimientos hospitalarios del último tercio del siglo XIX. En consecuencia, no resultaba extraño que los médicos, en pleno proceso de legitimación social, hicieran hincapié en las malas condiciones materiales y organizativas de los hospitales, acusando a esta organización de ejercer una mala administración.

Teniendo en cuenta las críticas de los facultativos, la Beneficencia, más que emprender una reforma total que abarcase la infraestructura y administración de sus establecimientos hospitalarios, se propuso mejorar las instalaciones de sus principales hospitales. Era tal el estado material de estos establecimientos que Pedro Gallagher, director de la Beneficencia de Lima en 1901, señalaba que los hospitales de la ciudad no se ajustaban a las "reglas que la ciencia y los adelantos de la civilización" (1901, p. XCIX). Incluso el Hospital Dos de Mayo, inaugurado en 1875 bajo los preceptos modernos de la época, que según el arquitecto García Bryce había marcado un "quiebre en la historia de la arquitectura hospitalaria limeña" (1967, p. 55), era considerado atrasado, pues adolecía de "enormes defectos", tales como "su restringida aereación (sic), la deficiencia de su dotación de agua y de su servicio de desagües" (Gallagher, 1901, p. XCIX).

El caso del Hospital Dos de Mayo resulta representativo para entender los cambios que se estaban dando en los modelos arquitectónicos hospitalarios de inicios del siglo

\footnotetext{
4. Según la ley del 2 de octubre de 1893, las personas que aspirasen a ser miembros de las Sociedades Públicas de Beneficencia no debían de ser deudores ni tener juicios pendientes. (RFMIB, 1896, p. 35)

5. Para 1899 Ántero Aspíllaga, director de la Sociedad de Beneficencia de Lima, señaló que el Ramo de Suertes representaba la cuarta parte de los ingresos obtenidos por esta institución. (MSBPL, 1899)

6. El rol empresarial de la Sociedad de Beneficencia de Lima saldrá a traslucir en los últimos años del siglo XIX, con la inversión de sus fondos en bancos nacionales o extranjeros establecidos en Lima, o en la Caja de Ahorros de esta sociedad (MSBPL, 1896, p. 31).
} 


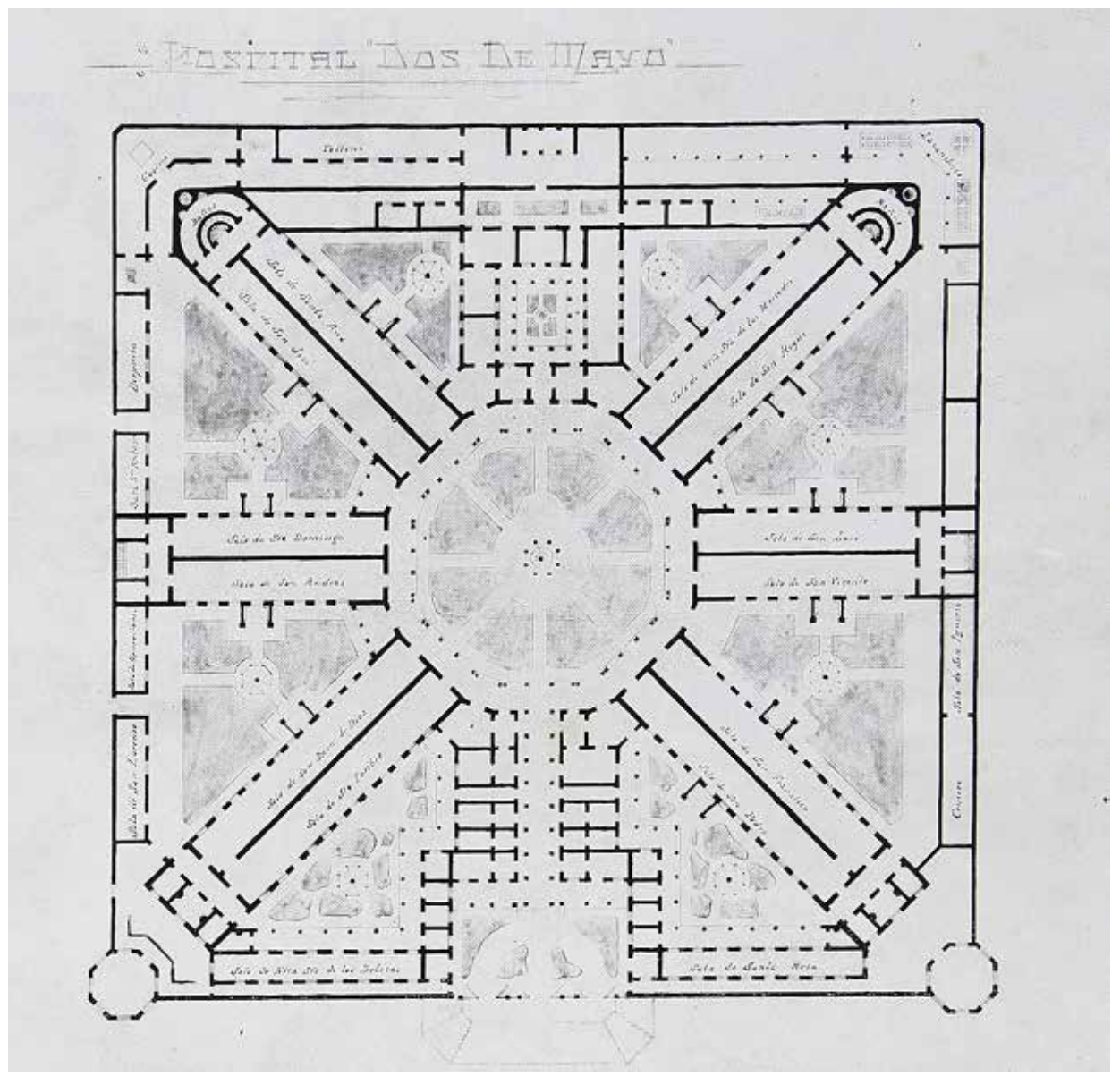

Figura 1. Plano del Hospital Dos de Mayo. En Álbum Fotográfico de los Establecimientos de su Cargo, por Sociedad de Beneficencia Pública de Lima, 1913, p. 5.

XX. Las críticas vertidas al hospital no solo estaban dirigidas a su condición material, sino a su modelo, que era de tipo radial, un derivado del modelo panóptico ${ }^{7}$. Desde la perspectiva de los médicos, este tipo de modelo no resultaba adecuado a las nuevas demandas de la ciencia médica. Por ende, se buscó reemplazarlo por uno de tipo abierto, como se señala más adelante ${ }^{8}$ (Figura 1).

El estado lamentable en el que se encontraban los hospitales y asilos de la ciudad, en relación a los lineamientos higiénicos de una ciudad moderna, llevó a que el Ministerio de Fomento y la Sociedad de Beneficencia de Lima, esta última con sus propios proyectos, buscaran corregir esta situación proponiendo la edificación de nuevos establecimientos hospitalarios. Es así que para finales del siglo XIX e inicios del XX se idearon tres grandes proyectos hospitalarios: el Hospital Nacional de Mujeres (futuro Hospital Arzobispo Loayza), el Hospicio Nacional de Tuberculosos (denominado después Hospital Domingo Olavegoya) y el Manicomio General (conocido posteriormente como Hospital Víctor Larco Herrera).

7. A decir de Carlos Aguirre (2015), el modelo radial no puede ser considerado como panóptico, a semejanza del diseñado por J. Bentham, pues no permite ejercer una vigilancia total ni permanente.

8. Cabe resaltar que hasta inicios del siglo XX los ingenieros y arquitectos siguieron apostando por el modelo panóptico, como se evidencia en sus proyectos de lazaretos y penitenciarias. A manera de ejemplo, se puede consultar los Anales de Obras Públicas de 1900, en el que figura el proyecto de lazareto del ingeniero Santiago Basurco. 


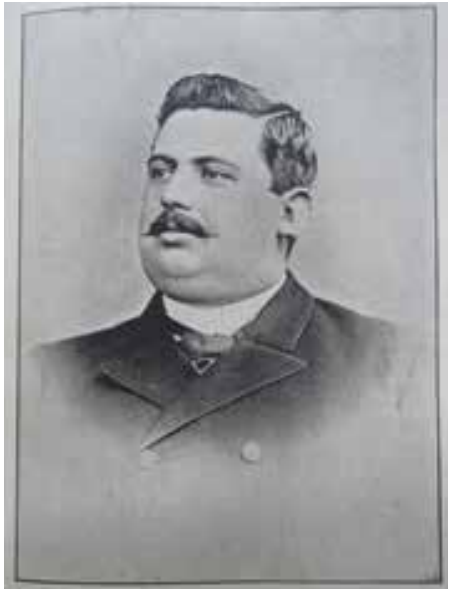

Figura 2. Retrato del Médico Manuel Antonio Muñiz “Dr. Manuel Antonio Muñiz", por D. M., 1897. La Crónica Médica, (204).
Este último proyecto sobresale por ser uno de los primeros propuestos e impulsados por el Ministerio de Fomento, a los pocos meses de su inauguración. La preocupación por el manicomio y, en consecuencia, por los "insanos" ${ }^{\prime \prime}$, no solo puede ser entendida en relación a los lineamientos de un Estado asistencialista, sino que debe considerarse en un ámbito más general de control social. La locura, ya constituida como "enfermedad mental", tras un proceso de medicalización que se remonta a la inauguración del Manicomio del Cercado $^{10}$ en 1859, fue considerada por los médicos y por las autoridades como una amenaza al orden social (Ruiz, 1994). La influencia de la teoría degeneracionista, que explicaba las afecciones mentales mediante una teoría de constante degeneración hereditaria del hombre, especialmente de ciertos grupos sociales, incentivó a llevar a cabo acciones para la prevención de la locura (Ríos, 2013). En consecuencia, para contrarrestar el avance de los insanos, ya no solo era necesario detectarlas tempranamente para interrumpir su desarrollo, sino que era indispensable evitar que sus víctimas reprodujeran este mal en sus parientes o futuros descendientes. La edificación de un nuevo establecimiento que pudiera tratar y resguardar a los insanos era ineludible, ya que el Manicomio del Cercado había entrado en una etapa de decadencia.

Al igual que los hospitales de la capital, el Manicomio del Cercado pasaba a fines del siglo XIX por un periodo de decadencia material que sumado a la sobrepoblación de sus espacios hacía insostenible su funcionamiento. Al ser el único centro dedicado al resguardo y tratamiento de los insanos a nivel nacional, su inoperancia resultaba significativa. En respuesta a esta problemática, el Ministerio de Fomento convocó en abril de 1896 a un concurso público "entre los médicos" con el objetivo de obtener un "estudio completo y circunstanciado sobre las condiciones a que debe de satisfacer una Casa de Insanos" (Muñiz, 1897a, pp. VII). El doctor Manuel Antonio Muñiz Sevilla, médico jefe del Manicomio de Lima de 1891 a 1897, fue el ganador del concurso con un proyecto titulado Asistencia Pública de los Enajenados ${ }^{11}$ (Figura 2).

La prematura muerte del médico Manuel Antonio Muñiz, a los pocos meses de haber ganado el concurso, impidió que pudiera participar en el proceso de construcción del nuevo Manicomio General. La materialización del proyecto de Muñiz duró alrededor de 22 años (1896-1918), tiempo en el que participó un conjunto de agentes profesionales dedicados exclusivamente al progreso material del país. Esta élite modernizadora, comandada por ingenieros, arquitectos y médicos, fue modificando a lo largo del proceso de construcción el proyecto original de Muñiz, sin alterar la esencia del mismo.

En cuanto al proyecto elaborado por Manuel Antonio Muñiz, es necesario tener en cuenta que a finales del siglo XIX el manicomio de modelo cerrado, tipo al que pertenecía el Manicomio del Cercado, era severamente cuestionado por la opinión pública debido a los constantes casos de maltrato y reclusión innecesaria que se daban entre sus muros ${ }^{12}$. Ante ello, se optó por un modelo de manicomio abierto, donde el insano pudiera gozar de una cierta libertad y, además, aprovechar los extensos campos de sus dominios para dedicarse al trabajo. Aunque la forma era distinta, el fondo era el mismo: el aislamiento (Figura 3).

9. A finales del siglo XIX e inicios del XX, los términos más usados por los médicos para referirse a las personas que trasgredían los parámetros de normalidad fueron: locos, insanos, amentes, idiotas, etc. A lo largo del texto emplearemos el término insano.

10. El nombre oficial del Manicomio del Cercado fue Hospital Civil de la Misericordia, pero también fue conocido como Manicomio de Lima u Hospicio del Cercado.

11. Inicialmente fue publicado en los Anales de las Obras públicas del Perú de 1896, bajo el título "Memoria Premiada. Bases para la Construcción de un Manicomio en Lima para 300 Enajenados".

12. Si bien estas críticas se daban principalmente en Europa, el Perú no fue ajeno a estos juicios. Tras ser internado en el Manicomio de Lima por casi medio año, en 1884, el escritor y hombre de ciencia Carlos Paz Soldán expuso con lujo de detalles su experiencia, haciendo hincapié en la violencia de la que fue víctima por parte de los guardianes. 


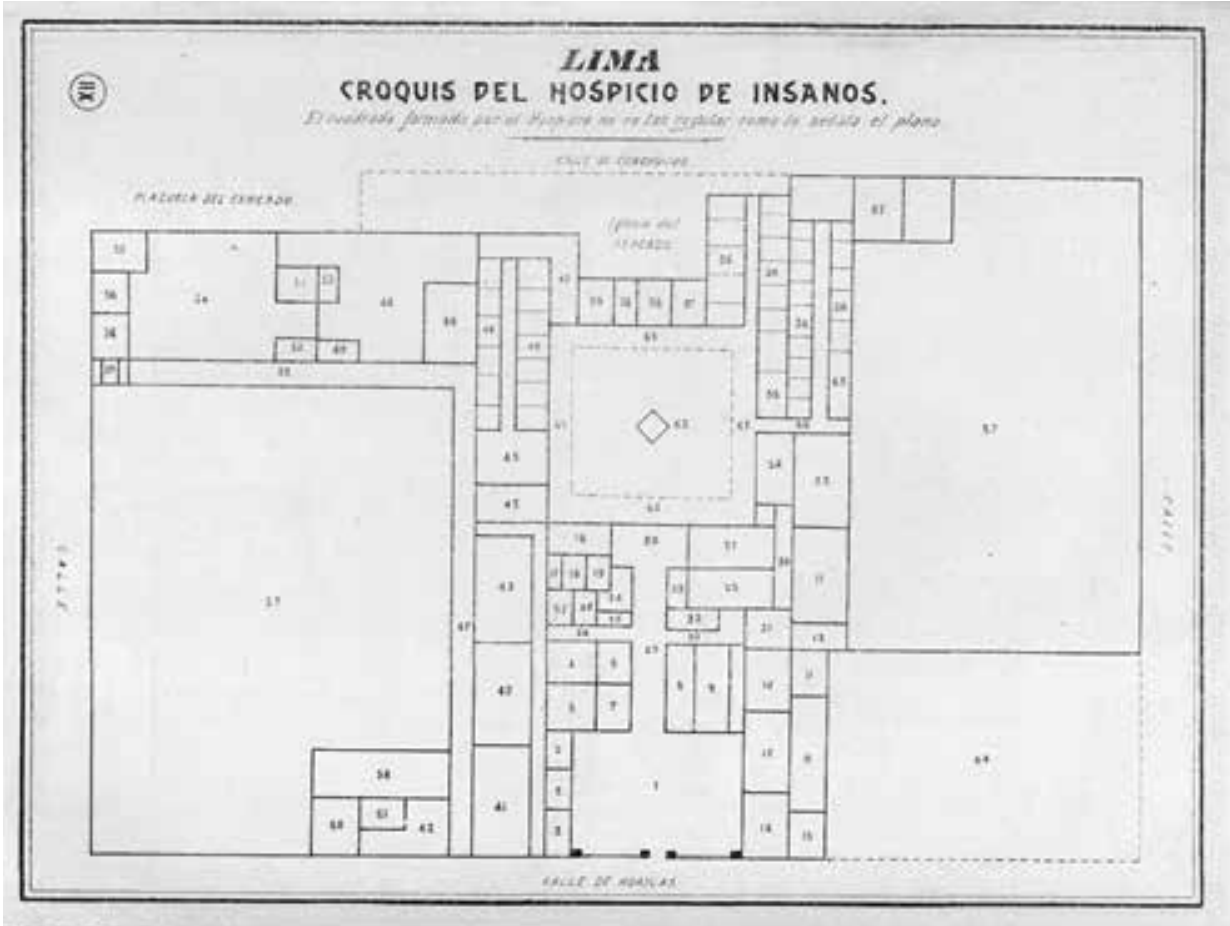

Figura 3. Plano del Hospicio de Insanos o Manicomio de Lima. En Asistencia Pública de los Enajenados. Concurso para la Construcción de un Manicomio (sección "Planos y croquis"), por M. A. Muñiz, 1897b.

\section{El proyecto de la "Casa de Insanos" de Manuel Antonio Muñiz}

En un extenso informe compuesto de cuatro secciones, el doctor Manuel Antonio Muñiz sintetizó todos sus conocimientos y experiencia adquiridos en su labor clínica en el Manicomio de Lima y en sus visitas hechas a los más importantes establecimientos psiquiátricos del mundo. Es en el tercer apartado de este informe donde se desarrollan las bases para construcción del Manicomio General (Figura 4).

Manuel Antonio Muñiz apostó por un asilo central de tipo abierto, compuesto por pabellones asimétricos, talleres y una sección agrícola, todo acogido por un ambiente natural donde los árboles frondosos abundaran y formaran extensas alamedas que dieran al insano la sensación de estar en libertad. Para materializar este gran proyecto, Muñiz pormenorizó las características que debía tener el asilo, describiendo las particularidades geográficas y su composición interna.

Por la dimensión del proyecto, el terreno que debía acoger el nuevo asilo estaba sujeto a ciertas exigencias. Muñiz establece que este "debe estar alejado de todo cerro, o construcción muy elevada, de toda arboleda muy tupida", de "cementerios, pantanos, muladares y basureros, camales y curtimbres y en general [de] todo establecimientos insalubre y mal sano" que interrumpieran el paso del viento o, en el peor de los casos, que lo contaminaran. El suelo debía ser "permeable y poroso" a fin de que sea seco y facilite la obtención de agua subterránea, por lo que se tenía que descartar un "suelo artificial" compuesto por la "hacinación de inmundicias" (Muñiz, 1897a, pp. 67-68).

Considerando estos detalles, Muñiz pasó a analizar el espacio geográfico de la ciudad de Lima, buscando las condiciones adecuadas para el asentamiento del nuevo asilo. Teniendo en cuenta la dirección de los vientos dominantes, la composición del suelo y los preceptos higiénicos, estableció que el mejor espacio para su edificación se encontraba entre el Sur y el Oeste de la ciudad. Así, determinó que los terrenos com-

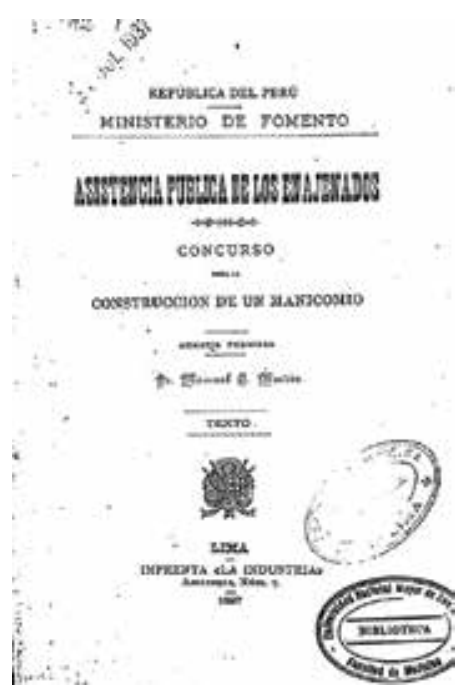

Figura 4. Portada del proyecto Asistencia Pública de los Enajenados presentado al Ministerio de Fomento. En Asistencia Pública de los Enajenados. Concurso para la Construcción de un Manicomio (sección "Planos y croquis"), por M. A. Muñiz, 1897b. 
devenir Vol. 5, Nº10, JULIO - DICIEMBRE 2018, pP. 65-90 - Estudios I ISSN 2312-7562 | E-ISSN 2616-4949

UNIVERSIDAD NACIONAL DE INGENIERÍA, LIMA

DOI: https://doi.org/10.21754/devenir.v5i10.599

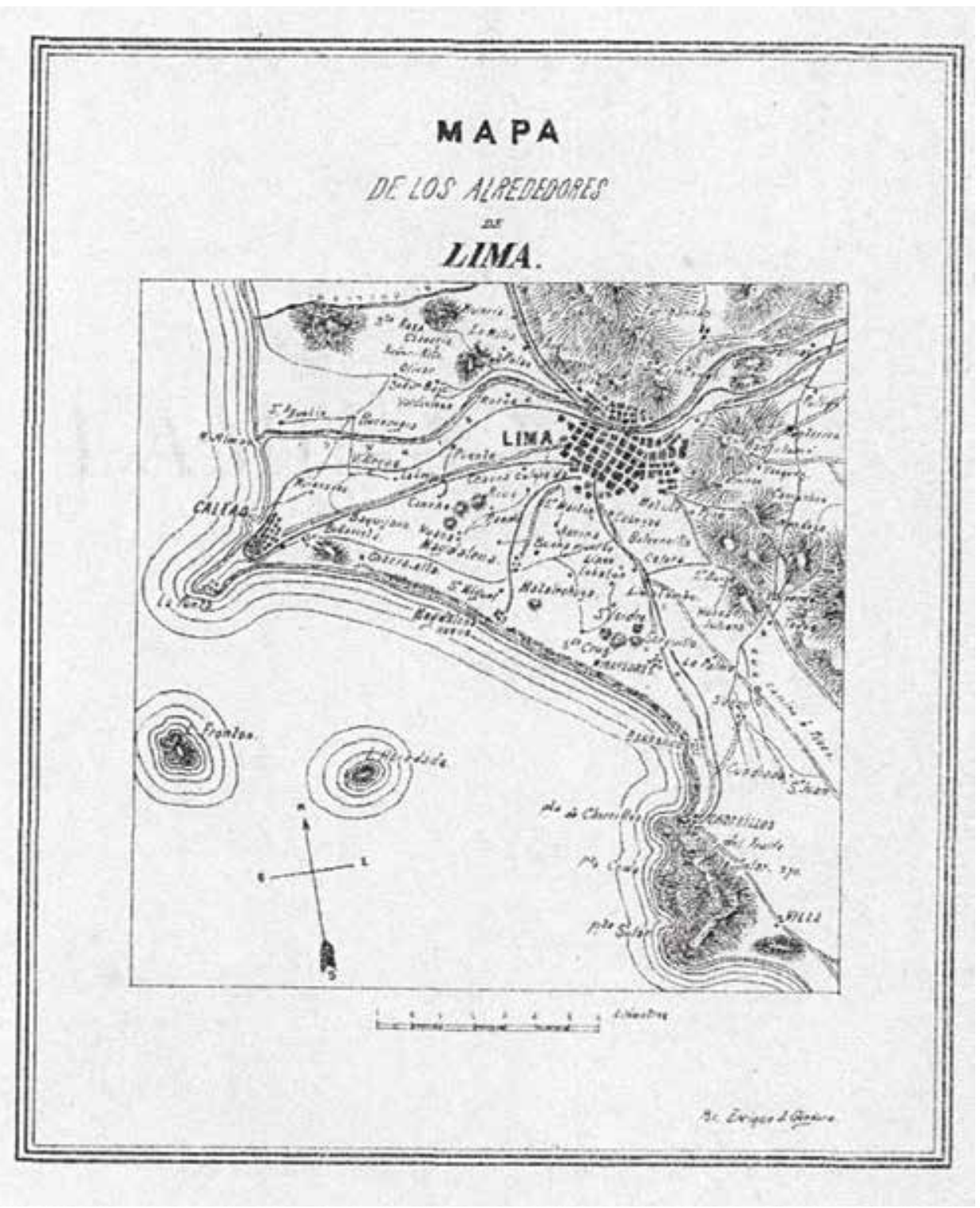

Figura 5. Plano de la ciudad de Lima. En Asistencia Pública de los Enajenados. Concurso para la Construcción de un Manicomio (sección "Planos y croquis"), por M. A. Muñiz, 1897b.

prendidos entre la Exposición, Santa Beatriz, Magdalena (Vieja y del Mar) y Miraflores cumplían con las condiciones deseadas, por poseer una "hermosísima perspectiva", un terreno "seco y permeable", y un nivel del agua subterránea profundo (1897a, pp. 7677). Es importante prestar atención al espacio escogido y a sus atributos naturales, pues uno de los problemas que se presentaron al momento de la edificación del asilo fue la elección del terreno y la disposición de agua (Figura 5).

El asilo de Muñiz estaba compuesto por dos partes bien diferenciadas, que serían la sección de asistencia y la sección agrícola. La primera de estas secciones estaría conformada por los servicios generales, y un conjunto de pabellones o cuarteles de clasificación y tratamiento. Como bien señala su nombre, los servicios generales contendrían todas las áreas encargadas de las actividades médicas y administrativas del asilo. Así, habría pabellones de "servicio médico y administrativo", del "cuerpo médico", de "la 


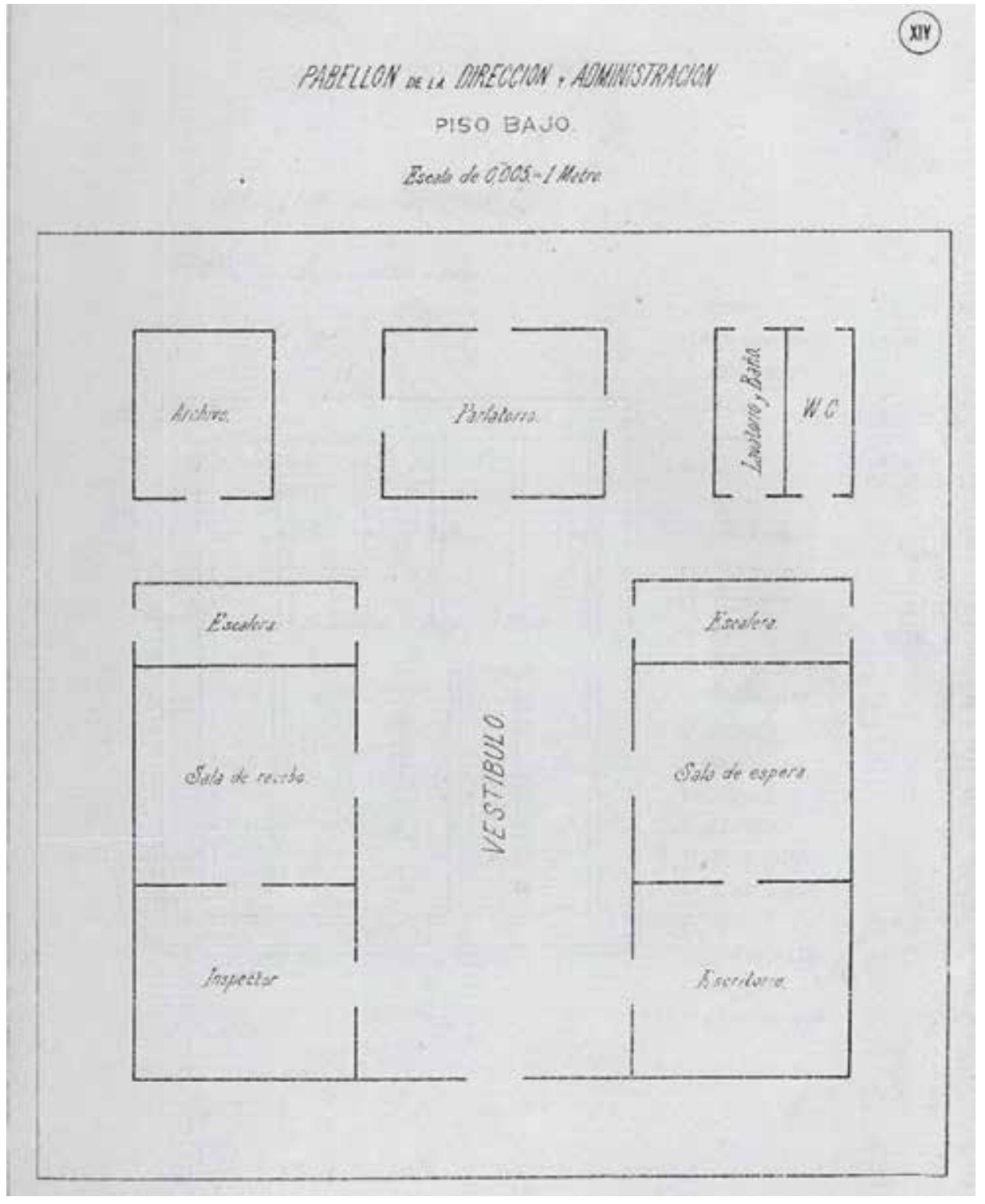

Figura 6. Plano del pabellón de administración. En Asistencia Pública de los Enajenados. Concurso para la Construcción de un Manicomio (sección "Planos y croquis"), por M. A. Muñiz, 1897b.

botica", de "operaciones", de "servicio electro-terápico", de "hidroterapia", de "la sección económica", y una "sala de fiestas y reunión" (Muñiz, 1897a, p. 81). Si bien los pabellones presentaban distintas formas de planta, la similitud de sus funciones implicó su ubicación al centro del asilo, pues permitía que el médico pudiera ejercer el control del hospital de forma práctica y rápida (Figura 6).

Los pabellones, o cuarteles de clasificación y tratamiento estarían divididos según la agrupación de los enfermos que plantearan los médicos. Ya desde mediados del siglo XIX, la estructuración del espacio manicomial presentó importantes cambios, como respuesta al desprestigio progresivo de la práctica asilar (Campos, 2001). La distribución hasta entonces empleada fue sustituida por una "clasificación empírica o práctica" que tenía que ver con las condiciones del enfermo, es decir, con su "estado general y sus capacidades de relación con los demás" (Navarro, 2015, p. 163). Muñiz fue cons- 
devenir Vol. 5, Nº10, JULIO-DICIEMBRE 2018, PP. 65-90 - Estudios I ISSN 2312-7562 | E-ISSN 2616-4949

UNIVERSIDAD NACIONAL DE INGENIERÍA, LIMA

DOI: https://doi.org/10.21754/devenir.v5i10.599

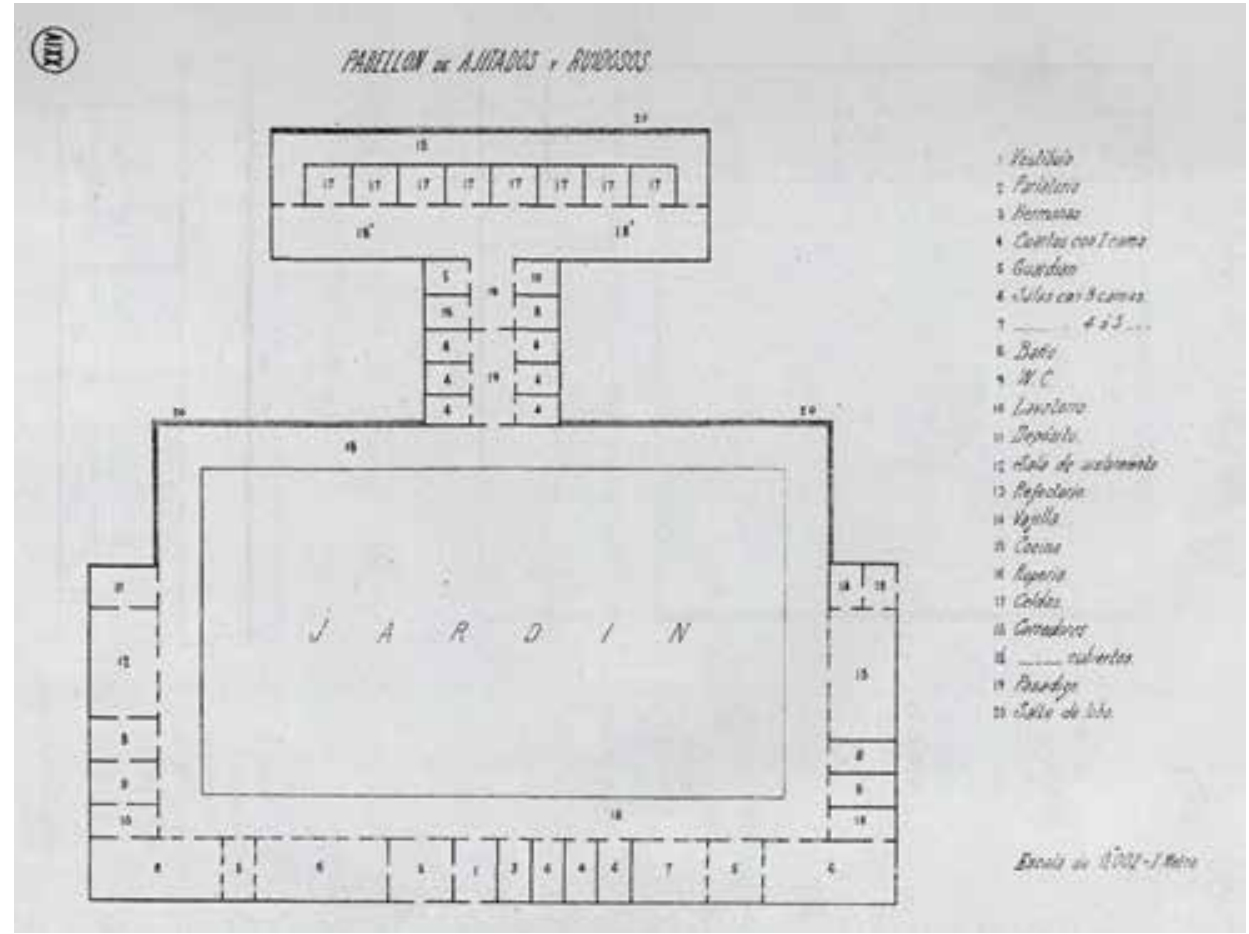

Figura 7. Pabellón de agitados y ruidosos. En Asistencia Pública de los Enajenados. Concurso para la Construcción de un Manicomio (sección "Planos y croquis"), por M. A. Muñiz, 1897b.

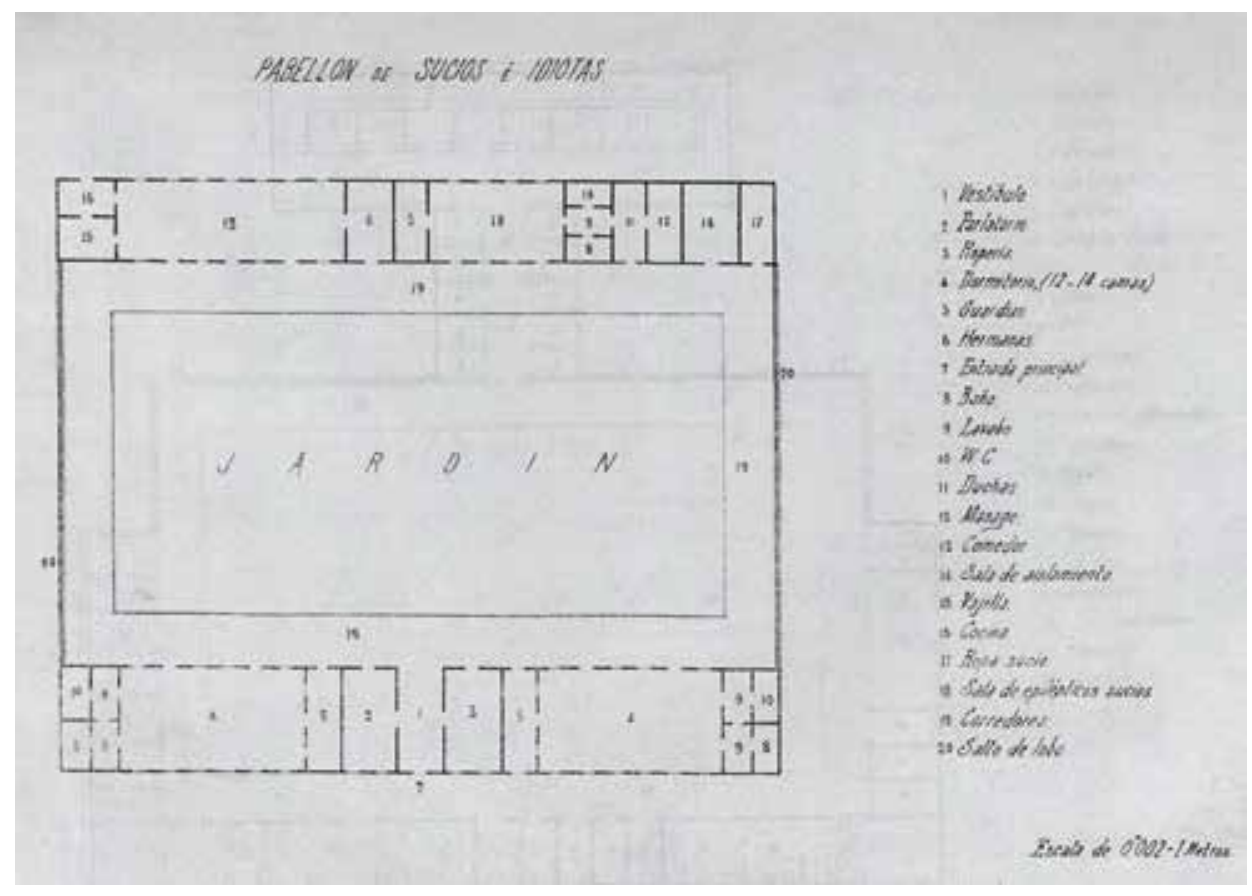

Figura 8. Pabellón de sucios e idiotas. En Asistencia Pública de los Enajenados. Concurso para la Construcción de un Manicomio (sección "Planos y croquis"), por M. A. Muñiz, 1897b. 
ciente de esto, pues proyectó agrupar a "los enfermos existentes en series naturales y sin mezclar enajenados cuyo contacto diario y continuo les sería perjudicial" (Muñiz, 1897a, p. 72). Así, planteó la existencia de cuatro pabellones para cuatro distintos tipos de pacientes: tranquilos, agitados, sucios e idiotas, y crónicos (ver Figuras 7 y 8 ).

A los edificios de clasificación se sumaron los de tratamiento. Los pabellones de enfermería y contagiosos se ubicarían, a pesar del inminente peligro de contagio, entre el pabellón médico y el de botica (Muñiz, 1897a, pp. 95-97). El pabellón de observación y vigilancia estaría destinado a "recibir a los pacientes nuevos, mientras se aprecian los elementos de su afección". Además, allí se asistiría a "todos aquellos que necesitan una vigilancia continua" (Muñiz, 1897a, p. 100). Este pabellón será considerado el más importante, por ser en él en donde se evaluaría el grado de desarrollo de las afecciones del paciente, para luego trasladarlo a un determinado pabellón de clasificación.

Si bien no se habían podido fundar hasta el momento colonias agrícolas ${ }^{13}$, a semejanza de la Colonia de Gheel, que el propio Muñiz pudo observar en su viaje a Bélgica, la instalación de una sección agrícola en el nuevo asilo resultaba relevante como un medio de trabajo para los insanos. El centro de la dependencia agrícola estaría compuesto por salas de instrumentos y de semillas, depósitos de cosechas y carretas, y corrales para caballos y ganado, con sus respectivos establos. El objetivo de esta sección era hacer trabajar al paciente, pues se consideraba que el trabajo tenía una doble ventaja: modificar "notablemente la marcha de la enfermedad" y generar pequeños ingresos económicos al alienado (Muñiz, 1897a, pp. 107-108).

Aunque no existía un número exacto de pabellones a construir, Muñiz calculó que serían un promedio de 30 edificios aislados y distribuidos en un área cuyo "eje trasversal (sic)" tendría una "extensión mínima de quinientos o seiscientos metros"14 (Muñiz, $1897 a$, p. 81). En estos edificios se albergaría un promedio de 400 alienados. El costo total de la obra, según el presupuesto de Muñiz (1897a), sería de 250,000 soles (Figura 9).

La muerte sorprendió a Manuel Antonio Muñiz antes de la ejecución de las obras del nuevo manicomio. Víctima de una "congestión cerebral", falleció el 17 de junio de 1897, con apenas 36 años de edad. ${ }^{15}$

\section{La construcción del Manicomio General}

A continuación, se describirá el proceso de construcción del Manicomio General. Para ello se ha dividido su desarrollo en tres apartados, en los que se puede observar claramente la interacción de los distintos agentes (ingenieros, arquitectos y médicos) que intervinieron en su materialización.

\section{Los primeros pasos: La elección del terreno y el inicio de las obras (1896-1902)}

A la elección del proyecto de Manuel Antonio Muñiz le siguió la creación, en octubre de 1896, de una comisión especial destinada a corregir, dirigir y concretar sus propuestas, pues -como habían resaltado los jurados del concurso- estas eran solo un "proyecto provisional" de muy grandes dimensiones y con un presupuesto impreciso (Muñiz, 1897a, pp. IX-XIII). Para la composición de esta comisión fueron nombrados el médico

\footnotetext{
13. En un artículo publicado en La Crónica Médica, en 1888, Muñiz reclamó la necesidad de crear colonias agrícolas al interior del país, específicamente en las montañas de Chanchamayo y Perené, o en los valles de Lima, Huacho, Arequipa o Piura. Las colonias agrícolas tenían como finalidad albergar especialmente a los pacientes calificados como incurables.

14. Esta extensión aproximada fue elaborada exclusivamente para la sección de asistencia; no se tuvo en cuenta la sección agrícola.

15. Acta de defunción, partida número 115.
} 


\section{SROQUIS}

PARA UN

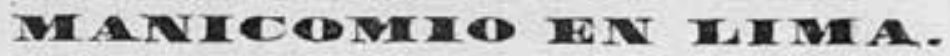

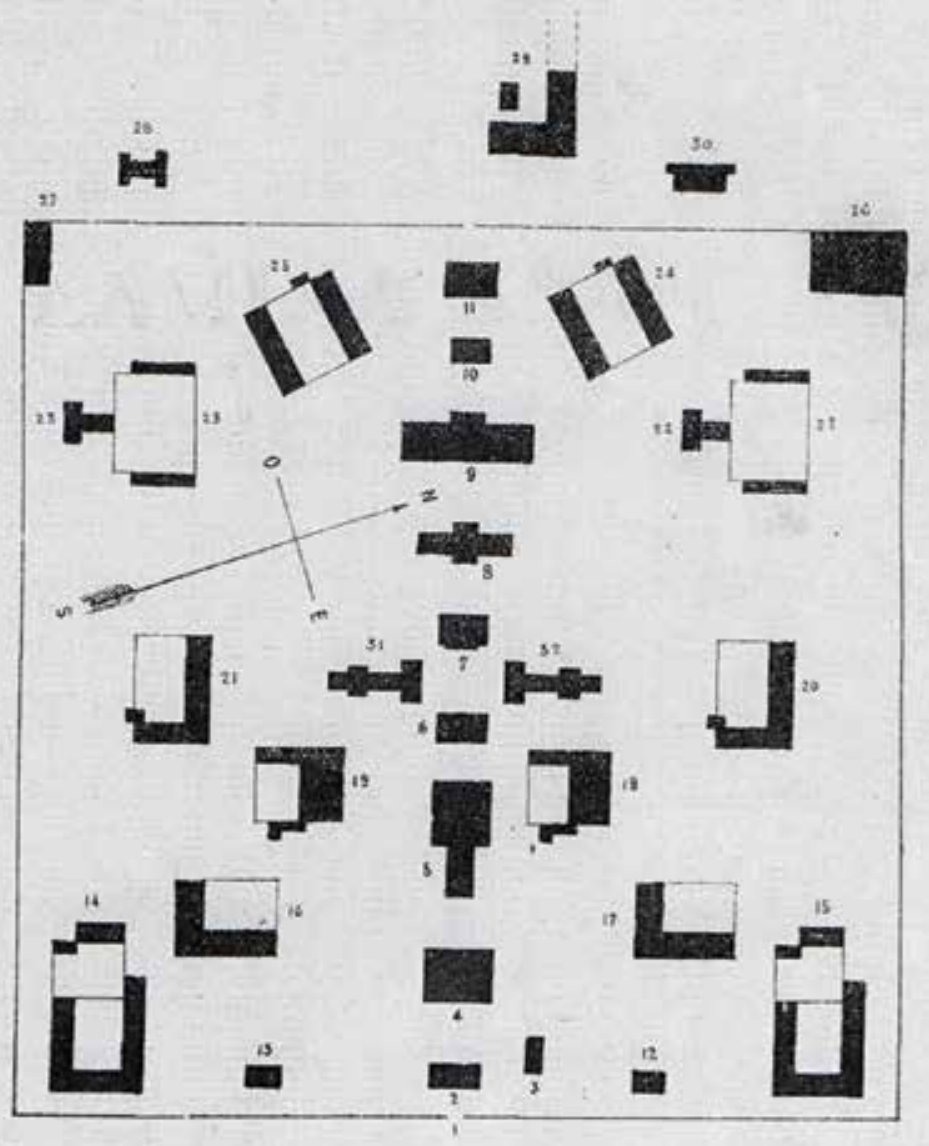

Figura 9. Distribución de los edificios propuestos por Manuel Antonio Muñiz en su proyecto del Manicomio General. En Asistencia Pública de los Enajenados. Concurso para la Construcción de un Manicomio (sección "Planos y croquis"), por M. A. Muñiz, 1897b.

Ricardo Flores Gaviño, futuro ministro de Fomento; el ingeniero José Castañón; y el médico alienista Manuel Antonio Muñiz. Para el diseño y presupuesto de la obra fue elegido el arquitecto Felix Gautherot, profesor de la Escuela de Ingenieros. A los pocos días, el 6 de octubre, se sumaron dos miembros más: el director de la Beneficencia de Lima, Carlos Ferreyros; y el inspector del Manicomio de Lima, N. de Aramburú (Cuadros, 1896, pp. 152-153). El objetivo de conformar esta comisión interdisciplinaria era complementar la experiencia administrativa y terapéutica de los médicos con la técnica y práctica de los ingenieros y arquitectos. 
El 30 de noviembre de 1896, la comisión especial emitió un nuevo proyecto, en el que manifestaba la elección de la Hacienda Santa Beatriz, "ubicada en la parte limítrofe con la Exposición y los fundos San Martín y Breña" (Ferreyros, 1896, p. 175), como el lugar más adecuado para la construcción del nuevo manicomio. Además, se estimó el costo total de las obras entre 600,000 y 700,000 libras peruanas, es decir, casi el triple del valor que Muñiz había establecido inicialmente.

En desmedro de la comisión, el Ministerio de Fomento creó el 11 de mayo de 1900 una Junta Económica encargada de "acordar lo conveniente a la designación y adquisición del sitio" donde se construiría el nuevo manicomio, y de administrar los fondos para este fin (Coronel, 1900, p. 118). La Junta Económica estuvo presidida por el director de Obras Públicas del Ministerio de Fomento, al cual se sumaron dos miembros de la Beneficencia de Lima (el filántropo Domingo Olavegoya y el inspector del Ramo de Suertes Guillermo Salcedo), un miembro de la Sociedad de Beneficencia del Callao (Mariano Valcárcel) y el arquitecto del Estado Maximiliano Doig, quien se encargó del aspecto técnico de la obra (Coronel, 1900). Fue este último quien elaboró "un plano artístico para un manicomio monumental, modificatorio del presentado por el doctor Muñiz, acaso superior", situado en las inmediaciones de Magdalena del Mar (Gallagher, 1900, p. LVI).

A diferencia de Muñiz y Gautherot, quienes optaron los terrenos en Santa Beatriz, Maximiliano Doig fue el primero en plasmar su preferencia por Magdalena del Mar. Esta elección no fue una simple casualidad. Ya habían pasado cuatro años desde la formación de la primera comisión de trabajo, y resultaba insostenible que para inicios de siglo todavía no se hubiese comenzado las obras. Por ello, lo primero que hizo la Junta Económica al tomar el control del proyecto fue elegir el espacio donde se edificaría el Manicomio General.

Por sugerencia de la Junta Particular de la Beneficencia de Lima, el doctor David Matto ${ }^{16}$, médico jefe del Manicomio del Cercado, pasó a integrar la Junta Económica como asesor del arquitecto Maximiliano Doig. El arquitecto y el cuerpo médico del Manicomio del Cercado, integrado por David Matto, Wenceslao Mayorga y Estanislao Pardo Figueroa, recorrieron a mediados de 1900 los ambientes de la ciudad que podrían servir para el nuevo manicomio. Visitaron los terrenos situados en la avenida Piérola y los "potreros del fundo de Desamparados", colindante con Santa Beatriz. Para sorpresa de la Junta Económica, Doig no tuvo en cuenta estos lugares y emitió el 31 de agosto de 1900 un informe señalando que el nuevo manicomio se construiría en los fundos de Orbea, Oyague y Matalechuza, ubicados en Magdalena del Mar (Gallagher, 1900). En respuesta a la decisión tomada por Doig, David Matto publicó un estudio que refutaba su decisión y convocó la participación de la Academia Nacional de Medicina.

La Academia Nacional de Medicina se pronunció en octubre de 1900 y, como era de esperarse, respaldó las propuestas de los médicos del Manicomio del Cercado. Resaltando la complejidad que había adquirido la medicina mental en los últimos años, desdeñó la participación de los ingenieros y arquitectos en la elección de la ubicación del Manicomio General, argumentando que "hoy no son... los más aparentes para dictaminar sobre lo concerniente a la instalación de los manicomios" (Carvallo, Flórez \& Castillo, 1900, p. 392). Todo lo contrario sucedía con los médicos alienistas, quienes se consideraba tenían "un mejor criterio" y podían "aconsejar lo que más convenga a las diferentes y complejas formas de las perturbaciones mentales" (Carvallo, Flórez \& Castillo, 1900, p. 392). El alienista, por lo menos en teoría, se alzaba sobre el personal técnico profesional (Figura 10).

16. A la muerte de Manuel Antonio Muñiz en 1897, el médico David Matto, quien para ese momento gozaba de un gran prestigio a consecuencia de su efectiva participación en el control de la epidemia colérica de Chile, fue elegido por la Sociedad de Beneficencia de Lima para reemplazarlo en la dirección del Manicomio del Cercado.

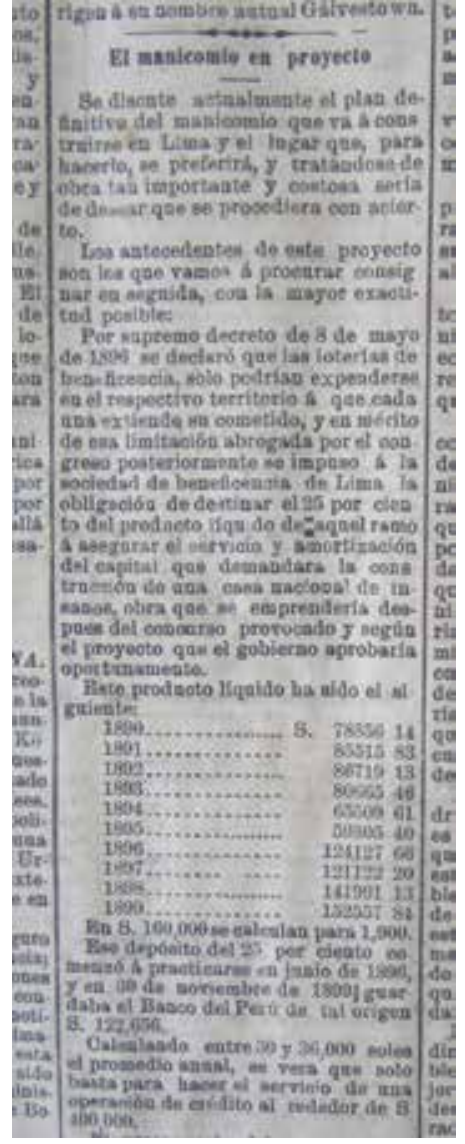

Figura 10. Cobertura sobre la elección del terreno para el nuevo Manicomio General. En "El Manicomio en Proyecto", 11 de setiembre de 1900. El Comercio, 1 
devenir Vol. 5, Nº10, JULIO - DICIEMBRE 2018, PP. 65-90 - EstudIOS I ISSN 2312-7562 I E-ISSN 2616-4949

UNIVERSIDAD NACIONAL DE INGENIERÍA, LIMA

DOI: https://doi.org/10.21754/devenir.v5i10.599

Por otra parte, la Academia Nacional de Medicina se pronunció a favor de que se construya en los terrenos de Santa Beatriz, exponiendo las desventajas de la ubicación de los predios de Magdalena, como la excitabilidad que ocasionaba en los insanos el "aire del mar" (Carvallo, Flórez \& Castillo, 1900). Además, añadió a esta "razón técnica" los beneficios que se podían obtener de los extensos campos de la Hacienda de Santa Beatriz: "Por su cercanía a Lima, puede dotarse de una buena provisión de agua a la vez que de magníficos medios de desagüe, elementos que creemos inútil manifestar su importancia" (Carvallo, Flórez \& Castillo, 1900, p. 392).

Con todas las ventajas presentadas, la Junta Económica eligió por voto los terrenos de Santa Beatriz (Olavegoya, 1900). Lamentablemente para los médicos, al estar la junta presidida por el director de Obras Públicas Teodorico Terry, se optó por desestimar el pedido, ya que los extensos campos de Santa Beatriz habían sido destinados para "la fundación de un instituto de agricultura teórico y práctico" (Tovar, 1900, p. 393), que vendría a ser poco después la Escuela de Agricultura. ${ }^{17}$

Para no entorpecer este proyecto, tomando como sustento las indicaciones de Manuel Antonio Muñiz en Asistencia Pública de los Enajenados respecto de la mejor ubicación del Manicomio General, el arquitecto del Estado Maximiliano Doig elaboró un informe en el que ubicaba al nuevo Manicomio General en Magdalena del Mar, específicamente en los fundos Oyague, Orbea y Matalechuza, lugar donde se encuentra actualmente el Hospital Víctor Larco Herrera (Tovar, 1901).

No tuvo que pasar mucho tiempo para que el Supremo Gobierno, por Resolución Suprema del 21 de diciembre de 1900, resolviera la ubicación definitiva del Hospital $\mathrm{Na}$ cional de Insanos siguiendo las recomendaciones dadas por Maximiliano Doig. De esta forma, se instó a la Junta Económica a comprar los fundos mencionados, que cubrían un área total de $850,481 \mathrm{~m}^{2}$. Así, el fundo Oyague, terreno de mayor extensión, que alcanzaba los $331,141 \mathrm{~m}^{2}$, fue comprado a Ismael Bielich ${ }^{18}$ por un valor de 15,000 soles; la finca Orbea, de $66042 \mathrm{~m}^{2}$, fue comprada a José A. de la Puente por 2,000 soles (Gallagher, 1901); y el fundo Matalechuza, propiedad del inspector Domingo Olavegoya, fue donado "con el carácter perpetuo e irrevocable y con la condición expresa de que dicho lote de terreno sea para incluirlo en la cuadratura del edificio del expresado manicomio" (Terry, 1901a, p. 306).

Como una forma de apaciguar las relaciones entre los miembros de la Junta Económica, pues la elección del terreno había agravado las contradicciones y disputas que existían entre el personal médico y técnico (ingenieros y arquitectos), se decidió aumentar el número de integrantes de la Sociedad de Beneficencia sumando tres miembros (Balta, 1901). Además, por ser esta Sociedad la que aportaba la mayor cantidad de dinero a los fondos del Manicomio General, se resolvió que entre sus miembros fuera elegido uno para cumplir la función de tesorero (Terry, 1901b). Así, en teoría, las beneficencias tendrían una mayor participación en las decisiones tomadas en la construcción del asilo, pero la realidad fue distinta. El Ministerio de Fomento, generalmente presidido por un ingeniero, fue el que tuvo el voto decisivo en la Junta.

Tras la elección y compra de los fundos de Magdalena del Mar, se pudo dar inicio a las obras de construcción del nuevo asilo. El 18 de agosto de 1901, a las 3 de la tarde en Magdalena del Mar, el presidente del Perú, el ingeniero Eduardo López de Romaña, puso la primera piedra del edificio destinado a ser el Hospital Nacional de Insanos

17. Como ha indicado José Ignacio López Soria, los terrenos de Santa Beatriz estuvieron destinados desde 1869 para el Instituto de Agricultura (2002).

18. En realidad el terreno pertenecía a la Universidad Mayor de San Marcos, que para finales del siglo XIX lo había cedido en orden enfitéutico a Ismael Bielich. Después de varias demandas la Junta Económica decidió expropiar el terreno. 
(Acta de inauguración, 1901). A esta ceremonia acudieron las personalidades más representativas del Estado y de la sociedad, pues el acontecimiento era único. Después de casi medio siglo, desde la inauguración del Manicomio de Lima en 1859, el Perú iba a contar con un establecimiento moderno, acorde con los últimos preceptos establecidos por la ciencia psiquiátrica.

Desde agosto de 1901 hasta finales de 1902, las obras de edificación se llevaron a cabo a ritmo continuo pero no intenso. El ingreso de Domingo Olavegoya a la dirección de la Beneficencia Pública de Lima, en 1901, cambió rotundamente el estilo de trabajo, pues facilitó inicialmente la ejecución de las obras. En su primer año de gestión se pudo avanzar considerablemente la edificación del pabellón administrativo e iniciar los trabajos para la construcción de los pabellones destinados para los pensionistas. Hasta ese momento se había gastado un total de 154,604.94 soles (Olavegoya, 1902). Con la designación de David Matto como ministro de Fomento, en noviembre de 1902, las obras del Manicomio General pasaron a un periodo de revaluación que llevó al poco tiempo a su paralización.

\section{Una larga espera: Revaluación del proyecto y paralización de las obras (1903- 1914)}

Entre 1903 y 1914 las obras del nuevo Manicomio General quedaron paralizadas. Durante este periodo las obras ya edificadas y el resto del proyecto fueron reevaluados, lo cual trajo como consecuencia su suspensión. Dos fueron los principales problemas que amenazaron la ejecución de los trabajos: el alto costo del asilo planteado por $\mathrm{Mu}$ ñiz, lo que obligó a practicar recortes y modificaciones que atentaron contra el modelo original, y la carencia de un estudio serio sobre el suministro de agua con el que debía contar el Manicomio General de Magdalena del Mar. Por más de una década el proyecto quedó suspendido por la incapacidad de sus miembros para trabajar de manera conjunta, deponiendo sus intereses de grupo.

Al quedar suspendidas las obras del Manicomio General, el trabajo avanzado hasta finales del año de 1902 pasó a ser observado. Los gastos que habían demandado hasta el momento las obras Ilamaron la atención de la Sociedad de Beneficencia del Callao, que solicitó los servicios del ingeniero Agustín Espinoza para tasarlos. El informe de este ingeniero mostró una realidad preocupante: la improvisación dominaba la ejecución del proyecto. Espinoza encontró que la realización de las obras había pasado a manos de 13 empresas contratistas que al carecer de una vigilancia constante y un control adecuado de sus trabajos habían ejecutado obras "sin detalles técnicos" (Loredo \& Sánchez, 1904, p. 418).

Este panorama llevó a que el ministro de Fomento, el médico David Matto, tomara las riendas del proyecto y reestructurara la Junta Económica responsable de la situación. Para este fin, emitió el 21 de febrero de 1903 un decreto supremo que modificó la conformación de la junta, que ahora pasaría a ser integrada por tres miembros de las sociedades de Beneficencia de Lima, uno del Callao y un representante del gobierno. Para tener mayor libertad de acción la nueva Junta quedó exenta del control del Ministerio de Fomento.

La renuncia del arquitecto del Estado M. Doig en 1903 dio paso a que el ingeniero Dimas Villavicencio tomara la "vigilancia y buena ejecución de los trabajos del nuevo hospicio de insanos" (Olavegoya, 1904, p. 417). Con la formación de esta nueva junta se procedió a estudiar los principales problemas que amenazaban las obras del Manicomio General, uno de los cuales era el suministro de agua potable. La rápida elección de los predios de Magdalena del Mar, sin haber realizado un estudio profundo de su composición, sumado al desorden que imperó en las obras, explican la desatención a 
devenir Vol. 5, Nº10, JULIO - DICIEMBRE 2018, PP. 65-90 - EstudIOS I ISSN 2312-7562 | E-ISSN 2616-4949

UNIVERSIDAD NACIONAL DE INGENIERÍA, LIMA

DOI: https://doi.org/10.21754/devenir.v5i10.599

esta problemática. Para darle una solución inmediata se procedió a realizar una serie de estudios técnicos ${ }^{19}$.

Estos estudios y la tasación de las obras visibilizaron la verdadera dimensión del proyecto del Manicomio General:

Si nos fijamos en que el terreno ocupado por el Hospicio tiene 600 metros de largo por 400 de ancho ${ }^{20}$ y que en él debe colocarse otros 25 edificios de mayor o menor importancia, que habrá que construir un muro de circunvalación de dos mil metros, nivelar el suelo, construir desagües, estanques, etc., se puede afirmar que no se podrá concluir la obra con menos de un millón quinientos mil soles y en tiempo menor de 8 años, de trabajo activo y continuado. (Junta Económica, 1904, p. 419)

Para Domingo Olavegoya, director de la Beneficencia Pública de Lima, la terminación de las obras, por lo menos de los pabellones de pensionistas, resultaba poco menos que imposible a fines de 1903. Por ello, su suspensión era inevitable.

Con la finalidad de retomar las obras del manicomio con un costo menos elevado que el señalado por Domingo Olavegoya, la Beneficencia de Lima se propuso, a pedido de la Dirección de Obras Públicas del Ministerio de Fomento, evaluar las modificaciones que podrían realizarse a las edificaciones ya construidas y a las que aún estaban pendientes. A diferencia de lo sucedido en relación a la elección del terreno, cuando el personal de la Beneficencia salió en defensa de los lineamientos establecidos por Muñiz, ahora más bien buscaba modificar el proyecto.

Así, se propuso que el pabellón de administración, que ya se encontraba terminado, ya no solo sirviera a este fin, sino que en él funcionasen otras dependencias, como la botica, la capilla, los departamentos de médicos y religiosas, etc. Además de los dos pabellones de pensionistas, uno alojaría a los enfermos de paga y el otro a los menesterosos (Sosa, Loredo, Romero \& Castañón, 1905). El objetivo de la Beneficencia era reducir los gastos modificando el proyecto original, pues lo relevante era dar inicio a otras obras de igual envergadura ${ }^{21}$ (Figura 11).

Esta persistencia en reformar el proyecto del Manicomio Nacional duró hasta 1906. Ante la negativa de la Dirección de Obras Públicas para llevar a cabo las modificaciones planteadas, la Sociedad de Beneficencia de Lima protestó porque a la nulidad de las reformas se sumó el pago indefinido que esta debía otorgar para las obras de Magdalena del Mar. Para dar reinicio a la construcción del Manicomio General el Ministerio de Fomento resolvió, el 16 de febrero de 1906, continuar con las obras del "hospital de insanos con estricta sujeción al proyecto primitivo del doctor Muñiz", pero con el detalle de que este debía seguir el "modelo de pabellón mixto", pues "concilia las limitaciones económicas de la Beneficencia" (Balta, 1906, p. 190). Está claro que para poder continuar con las obras del nuevo manicomio se tuvo que ceder a las reformas impuestas por la Sociedad de Beneficencia, aunque estas fueran en contra del modelo planteado por Manuel Antonio Muñiz.

19. A pedido de la Sociedad de Beneficencia, el ingeniero Agustín Espinoza fue el encargado de realizar los estudios técnicos. Los ingenieros Teodoro Elmore y J.V. Maradiegue hicieron lo mismo, pero abarcando una extensión mayor: Magdalena Vieja y del Mar.

20. Esta extensión del terreno $\left(240,000 \mathrm{~m}^{2}\right)$ hace referencia solamente al espacio que alberga los edificios dedicados a la administración y asistencia de los enfermos; no toma en cuenta el dedicado a las actividades agrícolas.

21. El impacto de la peste bubónica, así como del sismo que azotó la ciudad de Lima en 1904, menguó el presupuesto de la Sociedad de Beneficencia de Lima, al punto que se tuvo que paralizar una serie de proyectos hospitalarios de gran importancia, como el Hospital Nacional de Mujeres y el Sanatorio Nacional de Tuberculosos. 


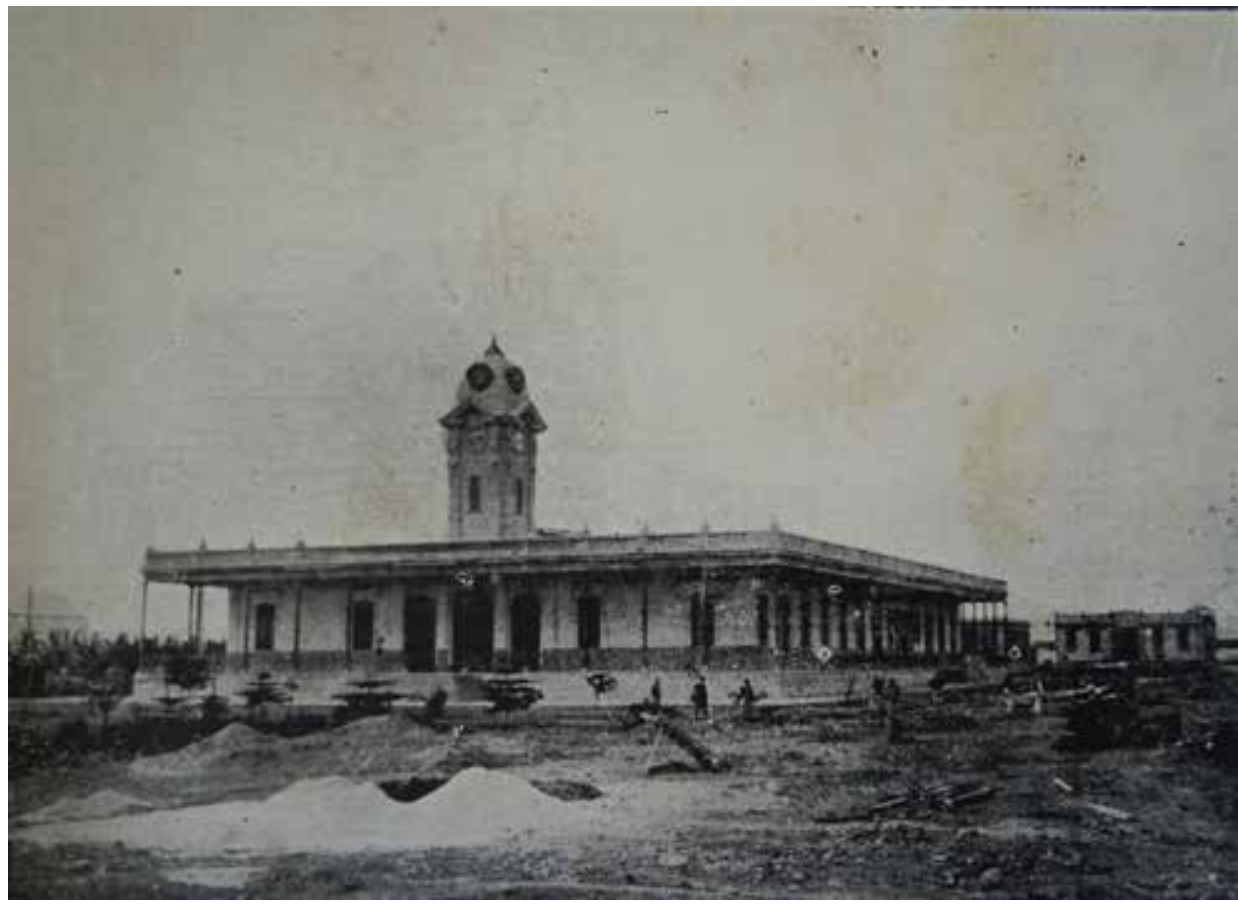

Figura 11. El pabellón de administración en 1915. Nótese el detalle de los obreros trabajando. En "Asilo Nacional de Insanos de la Magdalena", por F. Alayza. Memoria que el Ministro de Fomento ingeniero Sr. F. Alayza Paz Soldán presenta al Congreso Ordinario de 1915 (CCLXXIX-CCXCII), 1915.

A pesar de las medidas prescritas, las obras siguieron paralizadas, pues no se había solucionado el suministro de agua. Si bien existieron estudios dedicados específicamente a esta problemática, como los citados anteriormente ${ }^{22}$, se tuvo que esperar hasta 1910 para hallar una verdadera solución. El regreso del médico David Matto al cargo de ministro de Fomento a finales de 1909 favoreció a la solución de ese problema. A pedido de Matto, la Dirección de Salubridad procedió por intermedio del ingeniero Emiliano Buzzi a realizar un estudio de campo. Planteando que el mejor método posible para la obtención de agua era el profundizar los pozos y construir más galerías, se procedió a ejecutar dicha indicación. Aunque faltaban las máquinas necesarias para garantizar un suministro continuo, el Manicomio de Magdalena ya contaba para finales de 1909 con más de un millón de litros diarios de agua, suficiente para abastecer a una población de 5,000 habitantes (Tovar, 1910, p. CXII).

Por otra parte, la paralización de las obras dio inicio a un lento abandono de las instalaciones del Manicomio de Magdalena y a la depredación de sus fondos. Al estar gran parte del terreno del manicomio desatendido, pues hasta el momento solo se tenían tres pabellones edificados, se decidió arrendarlo. Al esto le siguió el abandono de las herramientas y materiales de trabajo, como la línea de Decauville y el hormigón. Pero lo más grave aconteció en 1912. Con el abandono total de las obras del manicomio, sus predios y edificios fueron cedidos para la creación de un higiocomio infantil. La vida del higiocomio fue corta, y en su lugar se creó un Escuela de Economía Doméstica que existió hasta 1914 (Valdivia, 1991).

22. Tanta era la preocupación de la Junta Económica por suministrar de agua al Manicomio General, que no dudó en plantear un proyecto de grandes dimensiones, como la instalación de una tubería de aproximadamente 4,000 metros de largo que uniera la toma de agua del parque de la Exposición con la de Magdalena. Como era de esperarse, esta idea no prosperó. 
devenir Vol. 5, Nº10, JULIO - DICIEMBRE 2018, pP. 65-90 - Estudios I ISSN 2312-7562 | E-ISSN 2616-4949

UNIVERSIDAD NACIONAL DE INGENIERÍA, LIMA

DOI: https://doi.org/10.21754/devenir.v5i10.599

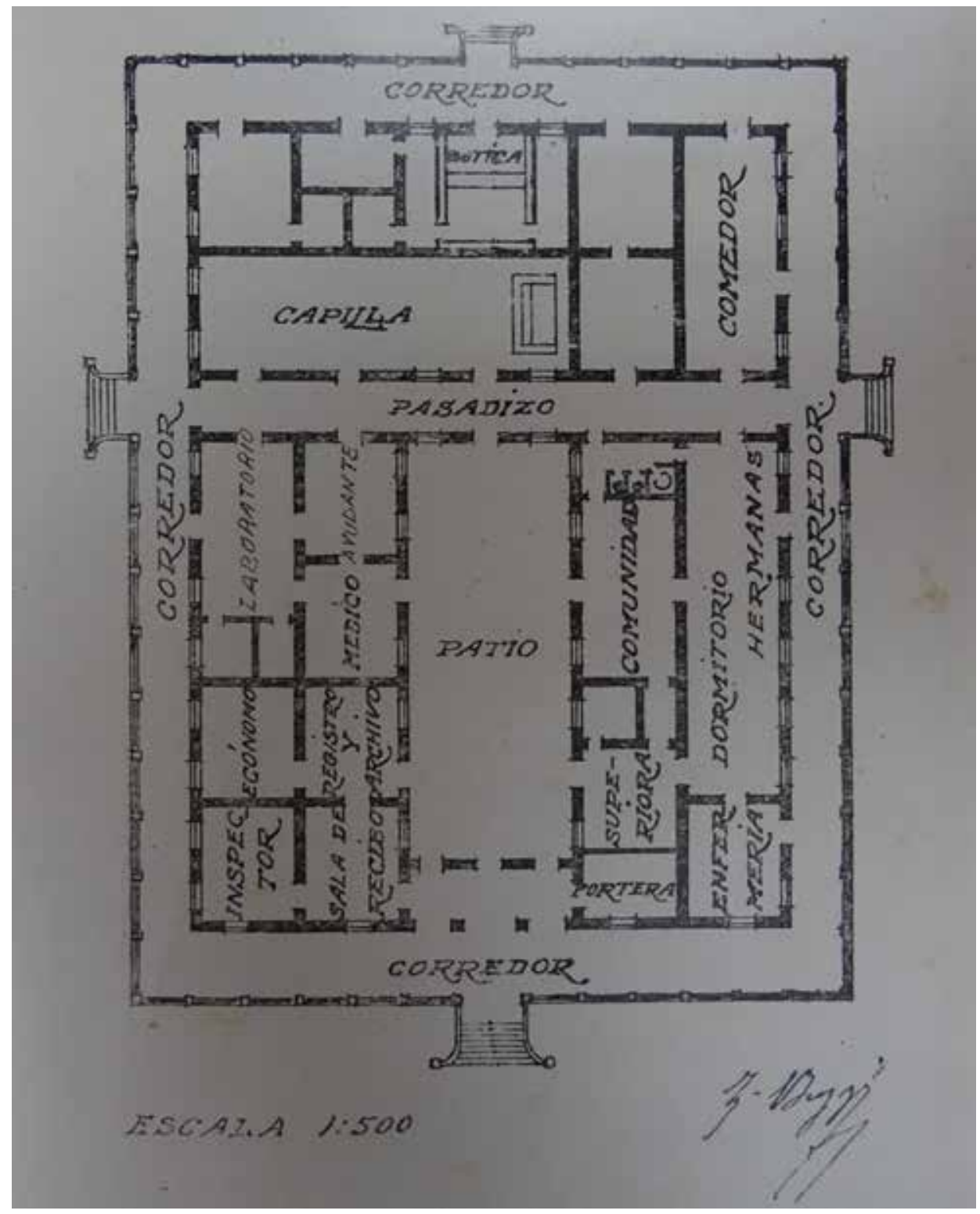

Figura 12. Plano del pabellón administrativo elaborado por el arquitecto Emiliano Buzzi. En Hospital Nacional de Alienados. Asilo Colonia de Magdalena, 1918.

Las constantes interrupciones de las obras del Manicomio General y, en consecuencia, la eterna prolongación de su inauguración, obligó a que las instalaciones del Hospicio del Cercado fueran renovadas para dar cabida al número creciente de insanos ingresados. Esto conllevó a que parte de los fondos destinados al levantamiento del Manicomio de Magdalena disminuyeran con el tiempo. Por otra parte, fue la propia Beneficencia la que se sirvió de estos fondos para cubrir gastos urgentes ${ }^{23}$. Ya sea por el abandono de las obras o por la depredación de sus fondos, la edificación del Manicomio General entró en una etapa de estancamiento de la que solo pudo salir en 1914.

23. Solo en 1907 se registraron tres préstamos, los dos primeros destinados a las beneficencias de Lima y Callao, y el último al Manicomio del Cercado. La suma total ascendía a un aproximado de 13,000 soles. 


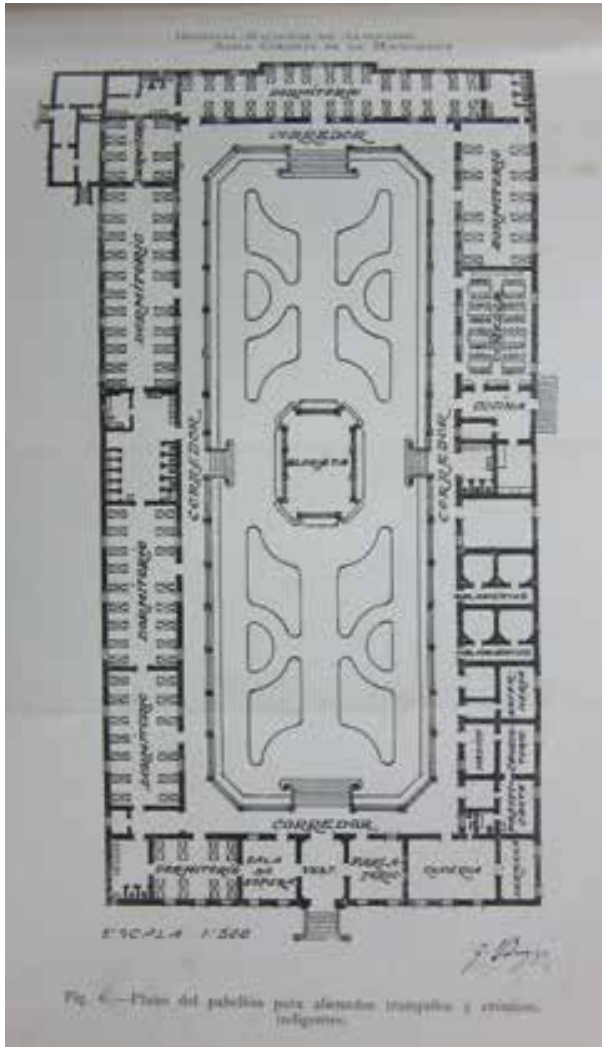

Figura 13. Plano del pabellón para alienados tranquilos, crónicos e indigentes. Nótese la aglomeración de las distintas categorías de alienados. En Hospital Nacional de Alienados. Asilo Colonia de Magdalena, 1918.

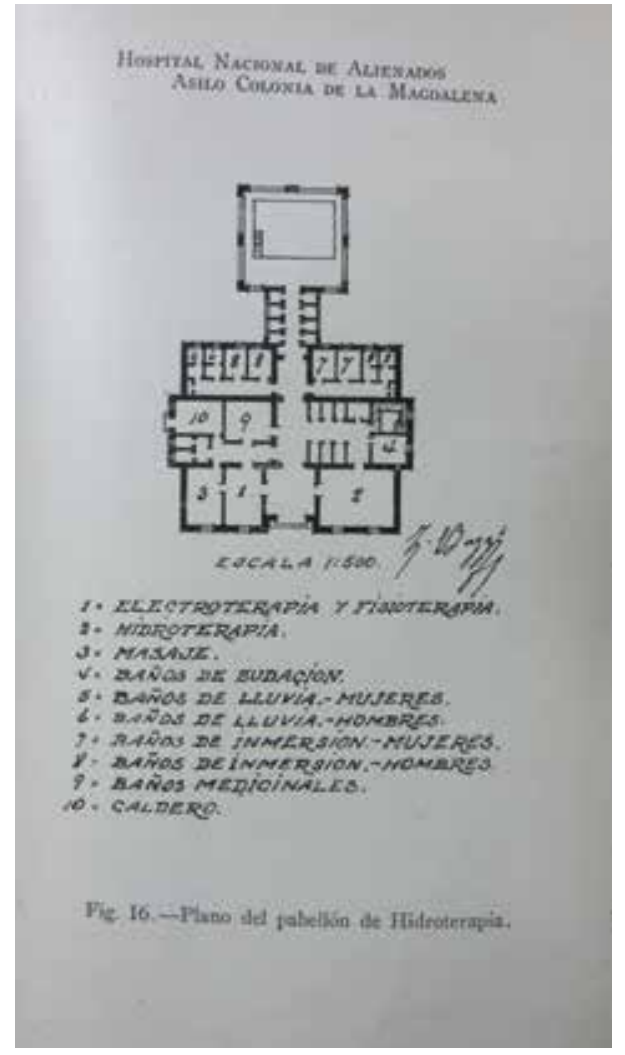

Figura 14. Plano del pabellón de hidroterapia. En Hospital Nacional de Alienados. Asilo Colonia de Magdalena, 1918.

\section{El reinicio de las obras y la inauguración del Asilo Colonia de la Magdalena (1914- 1918)}

Bajo el liderazgo del médico Abel Olaechea, director de Salubridad, las obras del Manicomio General fueron reiniciadas en los primeros meses de 1914. Luego de hacer las gestiones necesarias para eliminar la resolución suprema que había puesto fin a las obras del Manicomio, y de recuperar el inmueble del asilo cedido a las hermanas de la Orden Salesiana para el funcionamiento de una escuela doméstica, se pudo reflotar el proyecto. Por resolución suprema del 21 de marzo de 1914, se encomendó la dirección y ejecución de estas obras a una nueva comisión integrada por las autoridades más representativas del Ministerio de Fomento y la Sociedad de Beneficencia de Lima: los abogados Benjamín Boza y Federico Elguera; los médicos Abel S. Olaechea, David Matto y Baltazar Caravedo Prado; el ingeniero Agustín Espinoza; el arquitecto Rafael Marquina; y el futuro ministro de Hacienda Aurelio García y Lastres. A "causa de sus múltiples labores", el arquitecto de la Beneficencia Rafael Marquina tuvo que ser reemplazado por el arquitecto Emiliano Buzzi, quien se encargó de formular los planos y presupuestos de las nuevas obras del Manicomio General (Sociedad de Beneficencia Pública de Lima [SBPL], 1920, p. 3) (ver Figuras 12, 13 y 14).

A diferencia de las otras comisiones que comandaron las obras del Manicomio General, esta se mostró más receptiva a las reformas motivadas por causas económicas. El tiempo que duró la paralización de las obras del nuevo asilo enseñó a estas autoridades que era mejor contar con un edificio con ligeras modificaciones que no tener nada. 
devenir Vol. 5, Nº10, JULIO - DICIEMBRE 2018, pP. 65-90 - Estudios I ISSN 2312-7562 | E-ISSN 2616-4949

UNIVERSIDAD NACIONAL DE INGENIERÍ, LIMA

DOI: https://doi.org/10.21754/devenir.v5i10.599

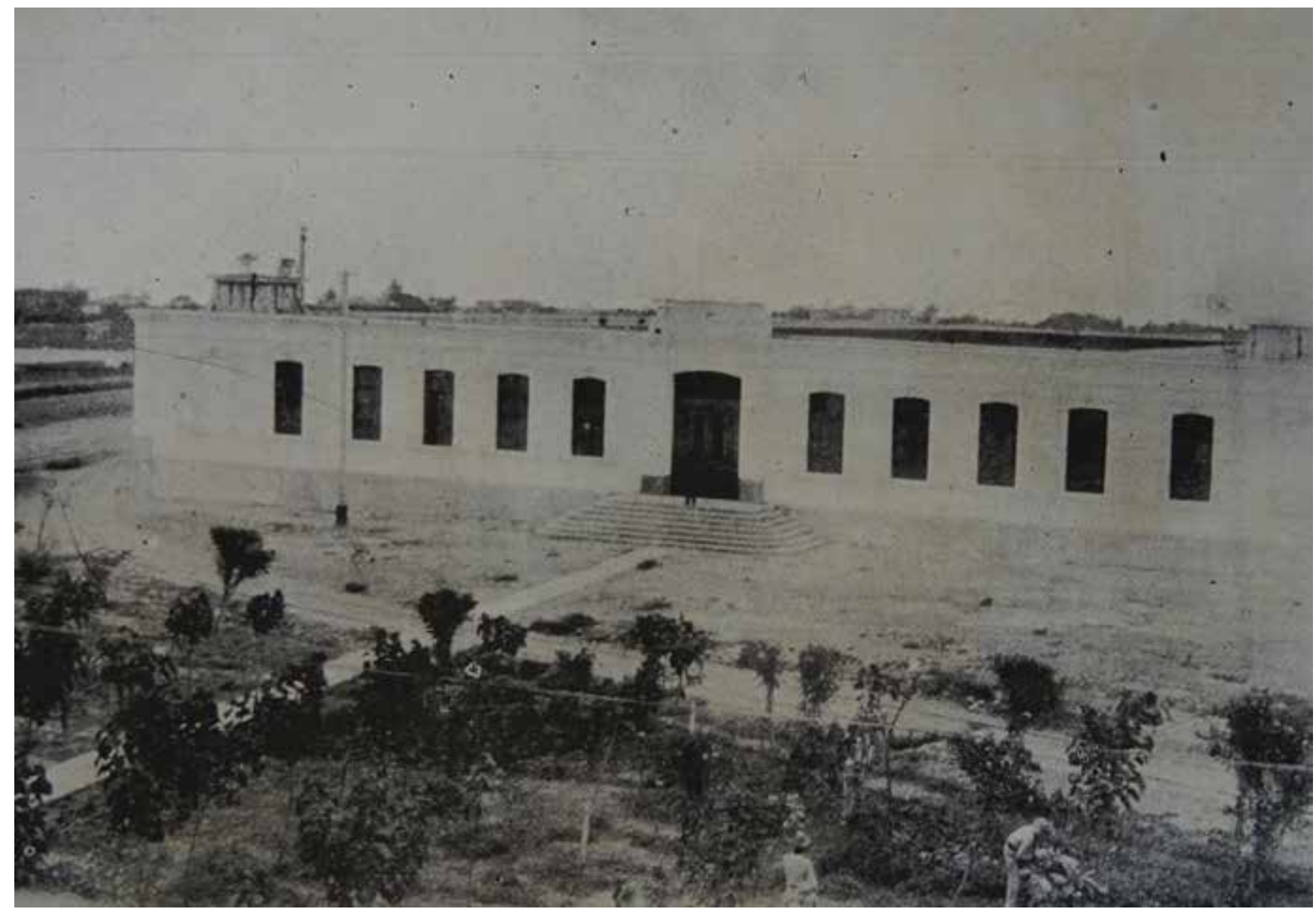

Figura 15. Pabellón de gratuitos y crónicos tranquilos. En "Asilo Nacional de Insanos de la Magdalena", por F. Alayza. Memoria que el Ministro de Fomento ingeniero Sr. F. Alayza Paz Soldán presenta al Congreso Ordinario de 1915 (CCLXXIX-CCXCII), 1915.
Por ello, al dar inicio a las obras, no dudaron en aplicar las reformas necesarias para que la propuesta coincidiera con el presupuesto asignado, sin que ello significara que el establecimiento fuese ajeno a los preceptos de la ciencia psiquiátrica.

Teniendo en cuenta los edificios ya construidos, la comisión ideó un proyecto que reordenaba el manicomio de manera que resultaba casi como lo había establecido Manuel Antonio Muñiz en su informe de 1896. El Manicomio General de la Comisión Olaechea sería un

Asilo mixto de hombres y mujeres separados en dos secciones completamente distintas, con pabellones diversos en cada una para categoría de enfermos, teniendo de común, únicamente, los servicios generales; administración, observación y vigilancia, mixto, hidroterapia, cocina. El asilo tendrá... los caracteres de los asilo-colonias, puesto que los alienados crónicos y tranquilos serán dedicados al trabajo agrícola. (Alayza, 1915, p. CCLXXXIII)

Siguiendo este orden, se procedió a adaptar los pabellones ya existentes, en primer lugar el "pabellón más avanzado de los construidos de acuerdo con el proyecto de Muñiz", que, tras una serie de modificaciones, pasó a convertirse en el edificio de "tranquilos, crónicos y gratuitos". Lo mismo sucedió con otro destinado inicialmente a los pensionistas, que por contar solo con las bases del edificio se convirtió en uno destinado a "enfermas tranquilas y crónicas". A estos dos se sumaron los edificios que fueron terminados en el primer año de trabajo de la Comisión: los pabellones de administración, de hidroterapia y de cocina (Alayza, 1915) (ver Figuras 15 y 16). 


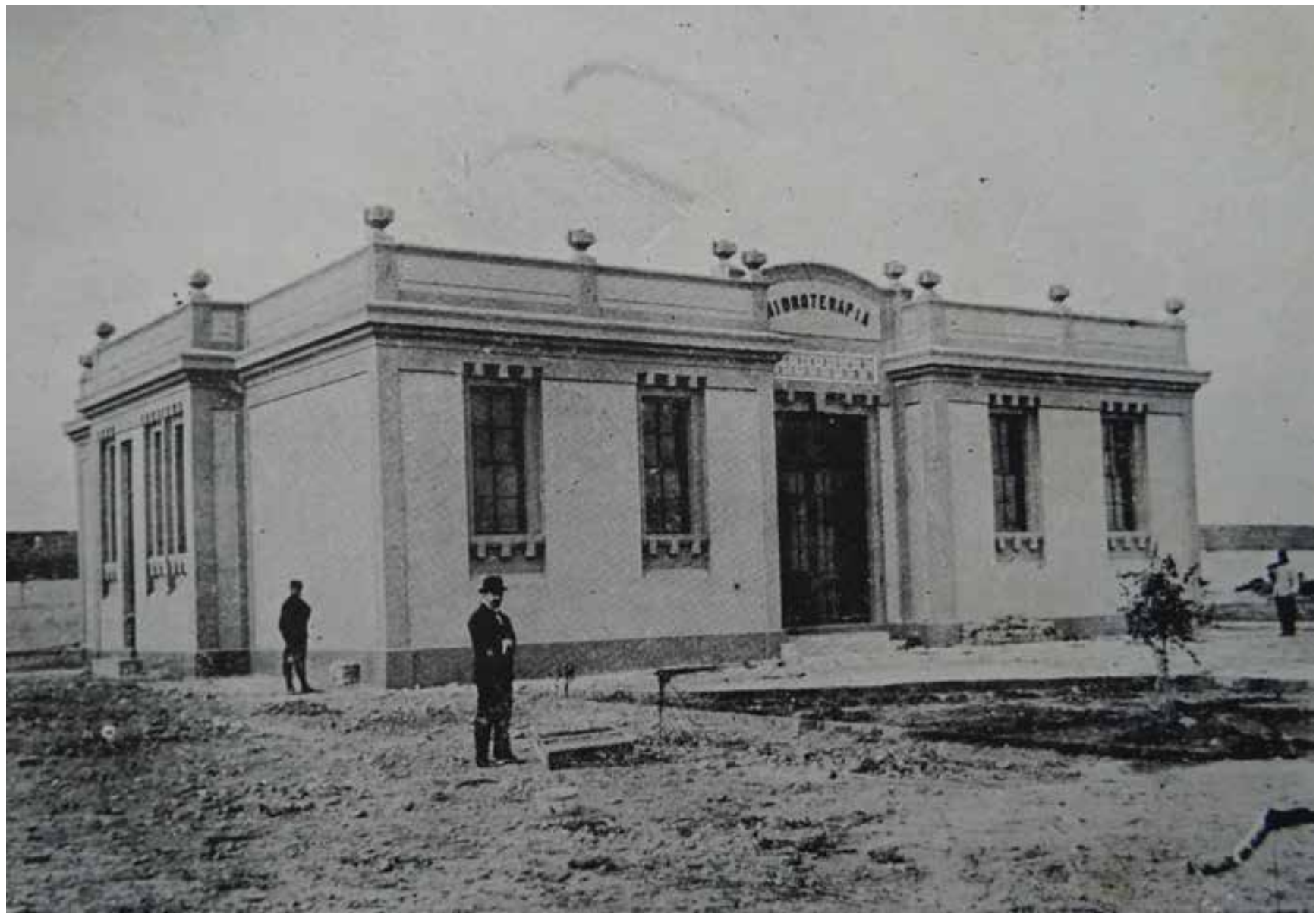

A finales de 1915, el Manicomio General contaba con todos los pabellones anteriormente mencionados. En menos de dos años la Comisión Olaechea pudo construir lo que no se pudo en más de una década, sin dejar de lado los detalles técnicos ni higiénicos que debía tener cada edificio. Aunque era claro que faltaba edificar algunos pabellones, el Supremo Gobierno dio por terminadas el 31 de diciembre de 1918 las obras del Manicomio General (SBPL, 1920) (ver Figuras 17, 18, 19 y 20).

Tras más de 20 de años de persistencia, el Manicomio General o Asilo Colonia de Magdalena fue inaugurado el 1 de enero de 1918. En un área de 289,183 $\mathrm{m}^{2}$ se construyeron 15 edificios dedicados a la asistencia y servicios generales ${ }^{24}$. A pesar de que las obras no habían sido culminadas en su totalidad ${ }^{25}$, los insanos del Manicomio de Lima fueron trasladados en los siguientes días al Asilo de Magdalena. Un diario de la época relató así este periplo:

A las cuatro de la madrugada de hoy fueron trasladados de su antiguo local del Cercado al nuevo manicomio de la Magdalena, más de ochenta locos, bajo la custodia de las madres del
Figura 16. Pabellón de hidroterapia. En"Asilo Nacional de Insanos de la Magdalena", por F. Alayza. Memoria que el Ministro de Fomento ingeniero Sr. F. Alayza Paz Soldán presenta al Congreso Ordinario de 1915 (CCLXXIX-CCXCII), 1915.

24. Un pabellón de administración, dos destinados a los "alienados crónicos y tranquilos", dos para "alienados pensionistas", dos para "alienados sucios e idiotas", uno para agitados, otro destinado a hidroterapia, una cocina, una lavandería una casa de portería, otra para el médico residente y un mortuorio.

25. Es recién en 1919, con los aportes del inspector del Asilo Colonia de la Magdalena, Don Víctor Larco Herrera, cuando las obras Ilegan a culminarse. Por ser parte de un proceso histórico distinto a lo planteado, conocido como la "reforma psiquiátrica" de 1919, no se tomó en cuenta estos cambios. 
devenir Vol. 5, Nº10, JULIO - DICIEMBRE 2018, PP. 65-90 - Estudios I ISSN 2312-7562 | E-ISSN 2616-4949

UnIVERSIDAD NACIONAL DE INGENIERÍA, LIMA

DOI: https://doi.org/10.21754/devenir.v5i10.599

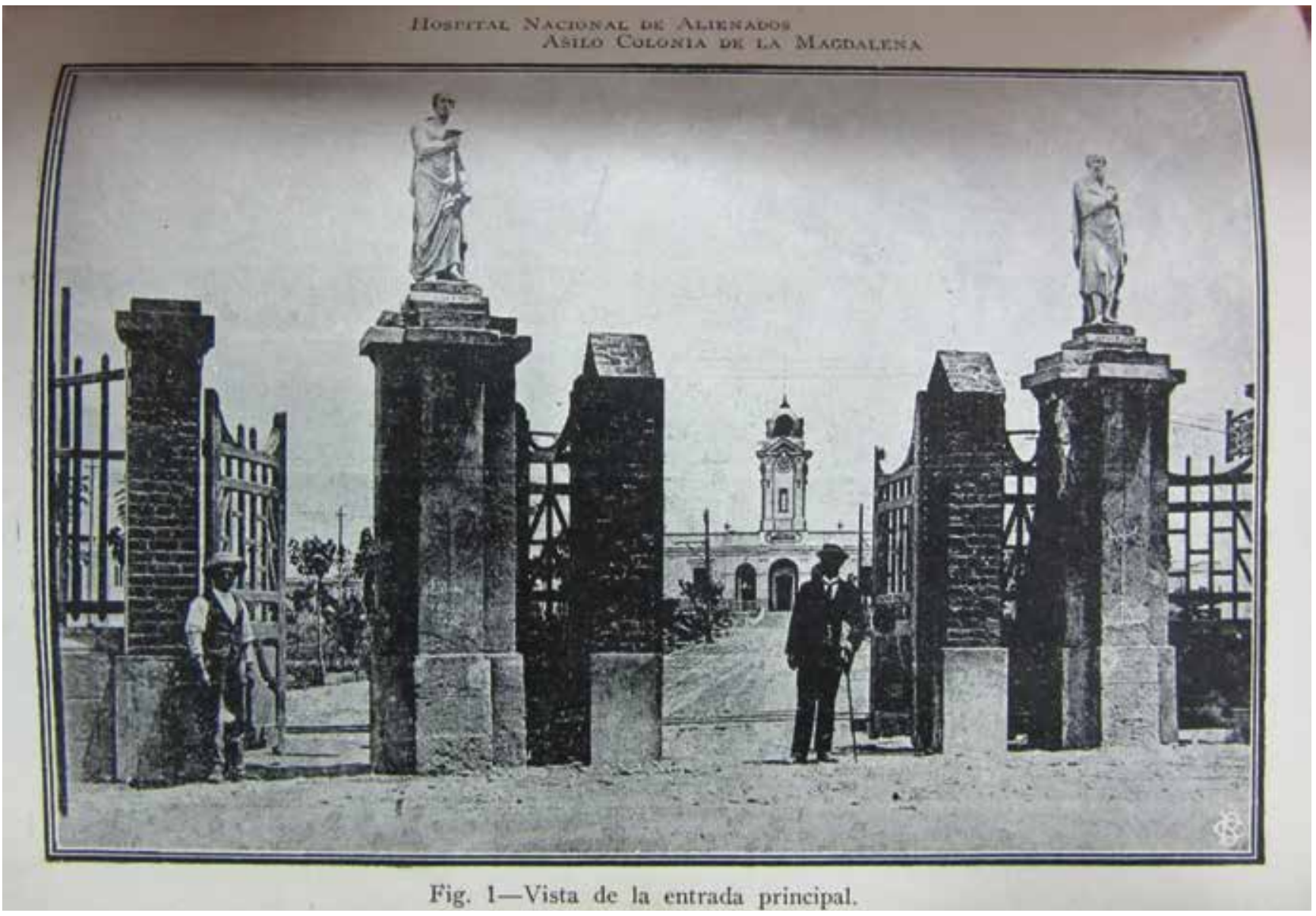

Figura 17. Entrada principal del Asilo Colonia de Magdalena. En Hospital Nacional de Alienados. Asilo Colonia de Magdalena, 1918.

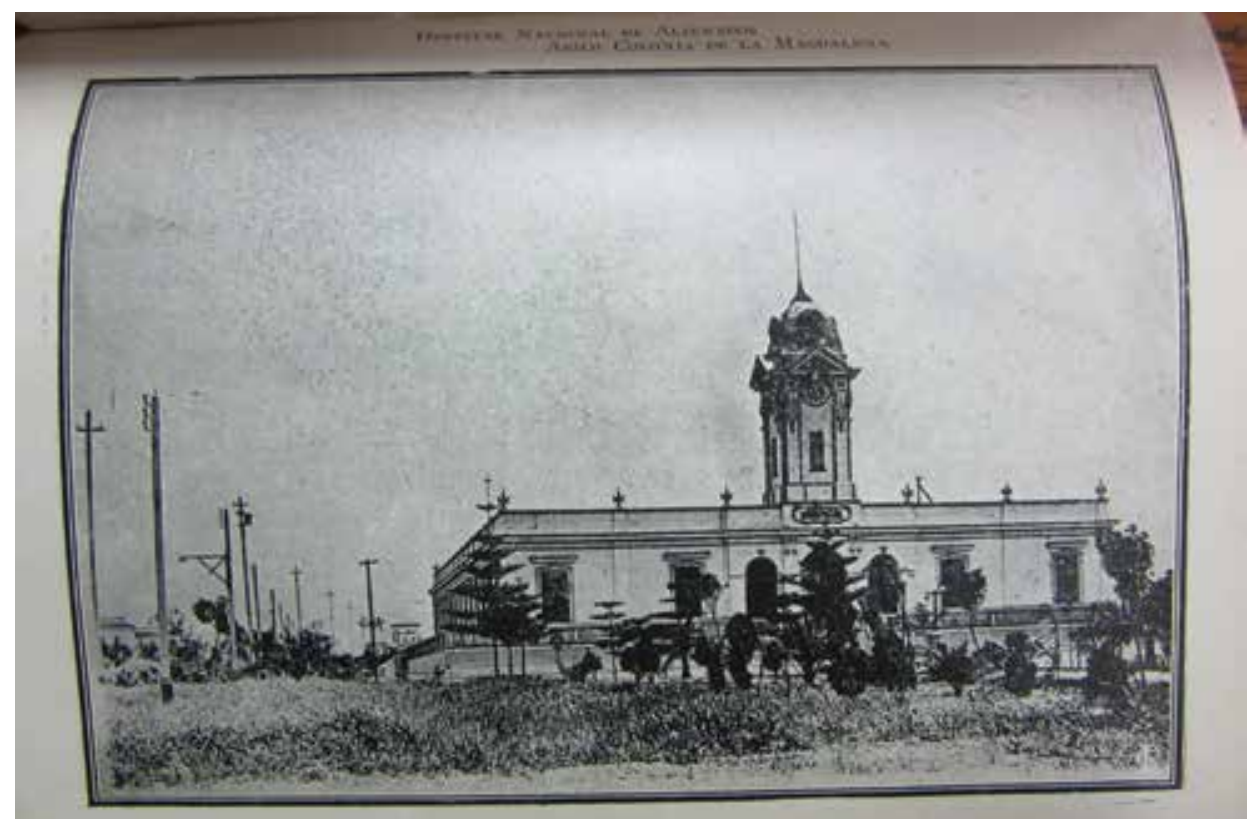

Figura 18. Pabellón de administración en el año de inauguración del Asilo Colonia de la Magdalena. En Hospital Nacional de Alienados. Asilo Colonia de Magdalena, 1918. 


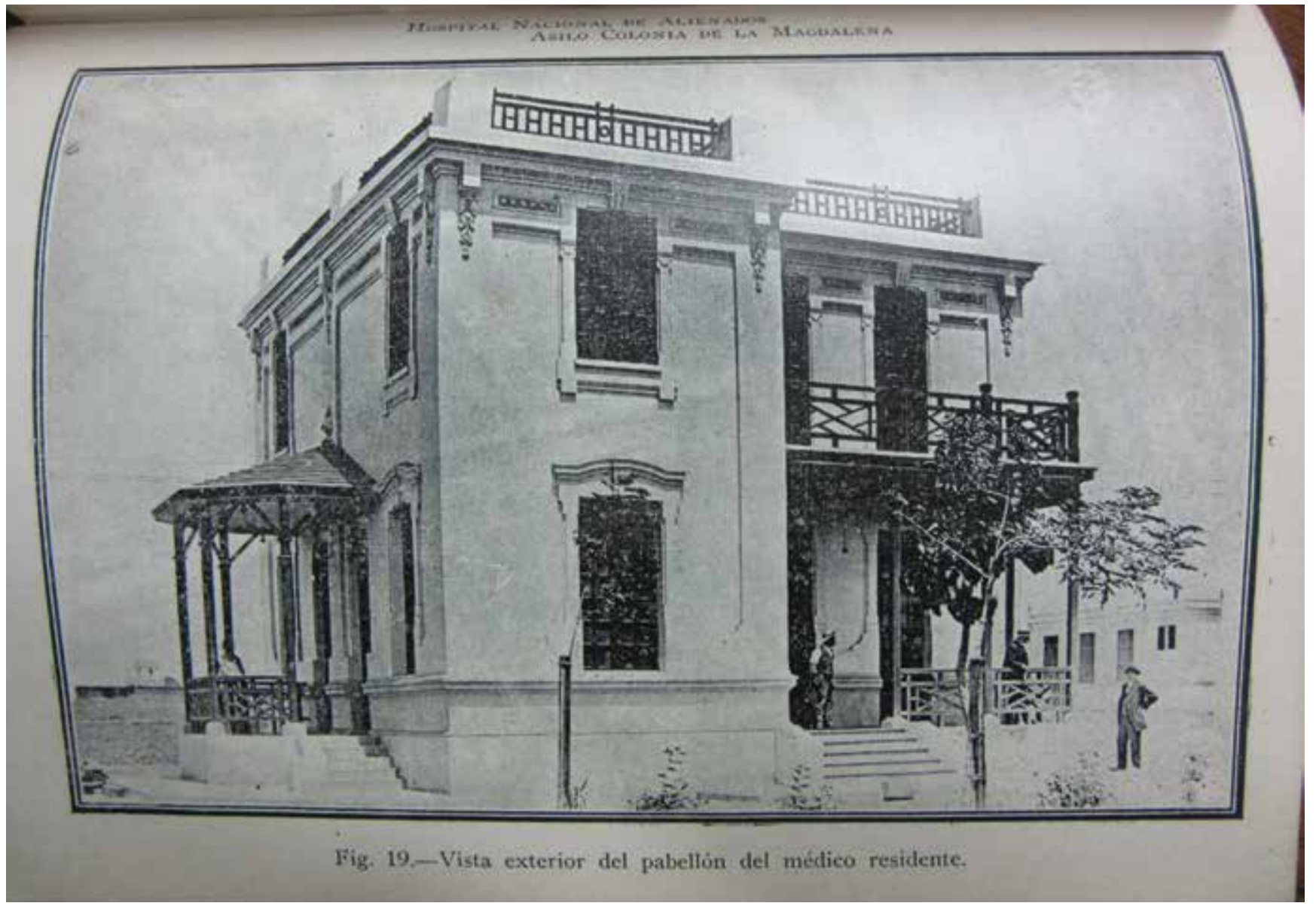

Figura 19. Pabellón del médico residente. En Hospital Nacional de Alienados. Asilo Colonia de Magdalena, 1918.

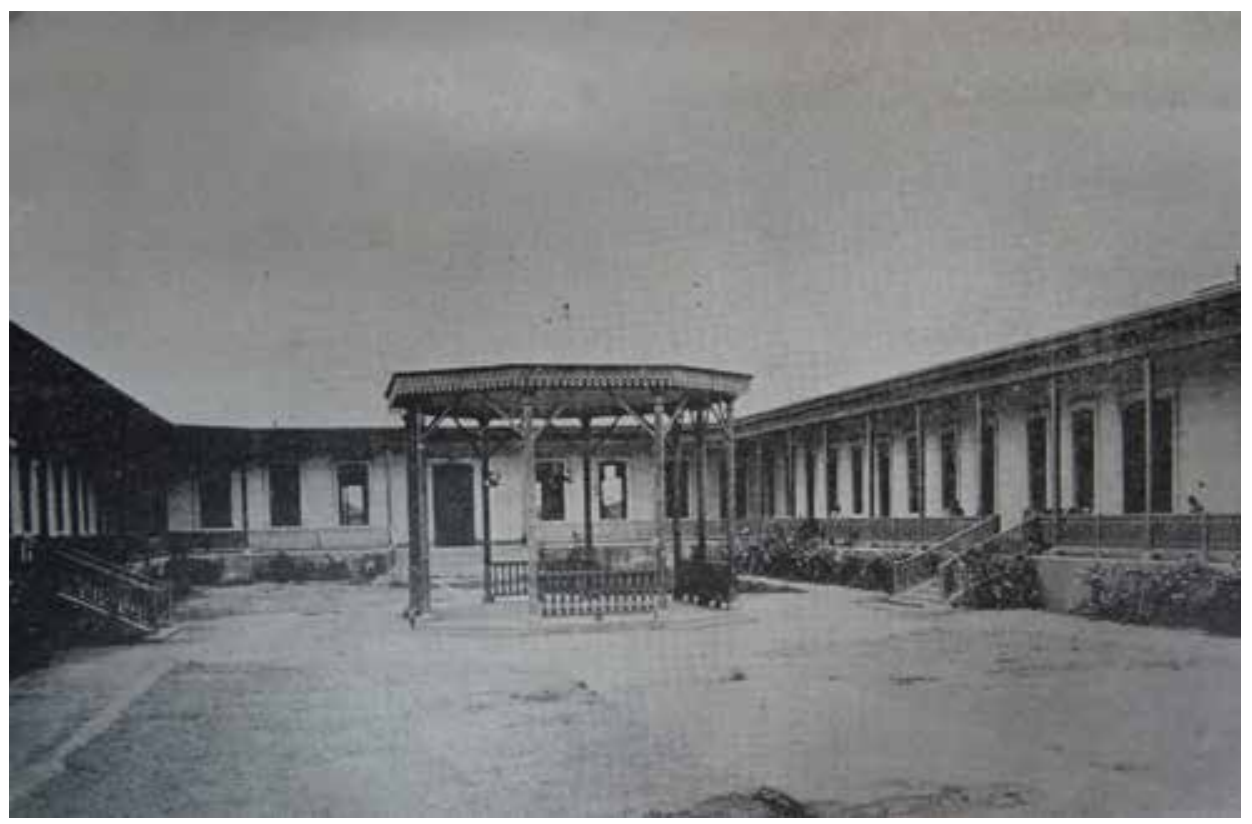

Figura 20. Interior del pabellón para alienados indigentes. En Hospital Nacional de Alienados. Asilo Colonia de Magdalena, 1918. 
devenir Vol. 5, Nº10, JULIO - DICIEMBRE 2018, PP. 65-90 - EstudIOS I ISSN 2312-7562 | E-ISSN 2616-4949

UNIVERSIDAD NACIONAL DE INGENIERÍA, LIMA

DOI: https://doi.org/10.21754/devenir.v5i10.599

establecimiento y de un competente número de guardias y gendarmes.... La mayor parte se condujo tranquilamente, mirando por las ventanillas del carro con enormes ojos sin expresión las calles solitarias, en las que apenas se veía uno que otro retardado que se paraba a mirar, impresionado, el extraño desfile. Cuando el convoy llegó al último paradero de la Magdalena, empezaba a amanecer. ("Traslación de Locos por las Calles de Lima", 1918, p. 3)

Los insanos habían llegado al Asilo Colonia de la Magdalena, y la locura con ellos.

\section{Conclusiones}

A lo largo del proceso de construcción del Manicomio General (1896-1918) se dio un diálogo constante entre ingenieros, arquitectos y médicos, que muchas veces se tornó tenso. Aunque estos profesionales manejaban un mismo discurso, el discurso del bienestar, la falta de un lineamiento claro en sus campos de acción (recordemos por ejemplo el protagonismo que habían adquirido los médicos como asesores en las obras de construcción de hospitales) provocó que se enfrascaran en una constante discusión, como la que se dio en torno a la elección del terreno idóneo. Un panorama distinto al señalado es difícil de imaginar, especialmente ante dos agentes que en los últimos años del siglo XIX e inicios del XX habían tomado un papel relevante en el proceso de modernización nacional, específicamente en cuanto a su desarrollo material. Solo era cuestión de tiempo, como se refleja en el periodo final de la construcción del manicomio (1914-1918), que estos profesionales pudieran dialogar de manera conjunta y, en consecuencia, materializar sus propuestas.

La edificación de un manicomio "moderno" que pudiera cumplir con todas las exigencias de su tiempo fue el ideal tanto de médicos como de ingenieros y arquitectos. Si bien la persistencia por materializar el proyecto de Muñiz se amparaba en un deseo por mantener el orden social, esta no estuvo exenta de buscar el bienestar de los llamados insanos. El asilo de tipo abierto se erguía como la mejor alternativa para tratar a los "enfermos de la mente" bajo los criterios científicos de la época.

En tiempos en los que el aislamiento terapéutico en manicomios y hospitales psiquiátricos ha sido dejado de lado por un sistema comunitario que apuesta por la promoción, prevención, fortalecimiento y descentralización de la salud mental, es indispensable reflexionar sobre el papel que deben de cumplir hoy esos establecimientos hospitalarios que antaño cumplieron una importante labor. Al cumplirse 100 años desde la inauguración del Hospital Víctor Larco Herrera, resulta relevante cavilar sobre su futuro para evitar que este caiga en la suerte de otros hospitales latinoamericanos que por dar paso a la "modernidad" fueron destruidos.

\section{Referencias}

Acta de inauguración. (1901). En Memoria administrativa que presenta a la Sociedad de Beneficencia Pública de Lima su director Don Pedro Gallagher correspondiente al año de 1901 (p. 305). Lima, Perú: Imprenta Liberal.

Aguirre, C. (2015). Apogeo, crisis y transformación del panóptico iberoamericano: Apuntes para la historia de un modelo arquitectónico. En J. Trujillo (Comp.), Voces y memorias del olvido. Historia, marginalidad y delito en América Latina. Guadalajara, México: Universidad de Guadalajara.

Alayza, F. (1915). Asilo Nacional de Insanos de la Magdalena. En Memoria que el Ministro de Fomento ingeniero Sr. F. Alayza Paz Soldán presenta al Congreso Ordinario de 1915 (CCLXXIX-CCXCII). Lima, Perú: Imprenta Americana.

Balta, J. (1901). Junta administradora. Resoluciones supremas. En Memoria administrativa que presenta a la Sociedad de Beneficencia Pública de Lima su director Don Pedro Gallagher correspondiente al año de 1901 (p. 299). Lima, Perú: Imprenta Liberal.

Balta, J. (1906). Manicomio Nacional. Resolución Suprema sobre la forma en que se continuarán los trabajos. En Memoria correspondiente al año de 1906 (pp. 190-191). Lima, Perú: s. e. 
Campos, R. (2001). De la higiene del aislamiento a la higiene de la libertad. La reforma de la institución manicomial en Francia (1860-1940). Frenia, I(1), 37-64. Recuperado de http://www. revistaaen.es/index.php/frenia/article/view/16355/16201

Carvallo, C.; Flórez, R.; \& Castillo, J. (1900). Informe de la Academia Nacional de Medicina. En Memoria administrativa que presenta a la Sociedad de Beneficencia Pública de Lima el primer vice director encargado de la dirección D. Pedro D. Gallagher correspondiente al año de 1900 (pp. 391-393). Lima, Perú: Imprenta Torres Aguirre.

Casullo, N.; Forster, R.; \& Kaufman, A. (2009). Itinerarios de la modernidad. Buenos Aire, Argentina: Eudeba.

Contreras, C. \& Cueto, M. (2015). Historia del Perú contemporáneo: Desde las luchas por la independencia hasta el presente. Lima, Perú: Instituto de Estudios Peruanos.

Coronel, E. (1900). Junta constructora del Hospital Nacional de Insanos. En Registro Oficial de Fomento. Sección Beneficencia (pp. 118-119). Lima, Perú: Imprenta de la Escuela de Ingenieros.

Cuadros, M. (1896). Comisión especial para formular el proyecto definitivo de la casa de insanos. En Registro Oficial de Fomento. Sección Beneficencia (pp. 152-153). Lima, Perú: Imprenta de la Escuela de Ingenieros.

El manicomio en proyecto. (11 de setiembre de 1900). El Comercio, 1.

Ferreyros, C. (1896). Memoria administrativa que presenta a la Sociedad de Beneficencia Pública de Lima su director Sr. D. Carlos Ferreyros correspondiente al año económico de 1896. Lima, Perú: Imprenta Liberal.

Foucault, M. (2002). Vigilar y castigar: Nacimiento de la prisión. Buenos Aires, Argentina: Siglo XXI.

Gallagher, P. (1900). Memoria administrativa que presenta a la Sociedad de Beneficencia Pública de Lima el primer vice director encargado de la dirección D. Pedro Gallagher correspondiente al año de 1900. Lima, Perú: Tomas Aguirre.

Gallagher, P. (1901). Memoria administrativa que presenta a la Sociedad de Beneficencia Pública de Lima su director Don Pedro D. Gallagher correspondiente al año de 1901. Lima, Perú: Imprenta Liberal.

García, J. (1967). Arquitectura en Lima, 1800-1900. Amaru, julio-setiembre (3), 49-56.

García, U. (2004). Salud. Enciclopedia Temática del Perú (Tomo XII). Lima, Perú: El Comercio.

Garfias, M. (2009). La formación de la universidad moderna en el Perú: San Marcos, 1850-1919 [Tesis de licenciatura]. Universidad Nacional Mayor de San Marcos, Lima, Perú.

Habermas, J. (2002). La modernidad, un proyecto incompleto. En H. Foster (Ed.), La posmodernidad (pp. 19-36). Barcelona, España: Kairós.

Hospital Nacional de Alienados. Asilo Colonia de Magdalena. (1918). Lima, Perú: La Opinión Nacional.

Junta Económica. (1904). Informe presentado al Ministerio de Fomento y a las Beneficencia de Lima y Callao. En Memoria administrativa que presenta a la Sociedad de Beneficencia Pública de Lima su director Don Domingo Olavegoya correspondiente al año de 1903 (pp. 418-422). Lima, Perú: Imprenta E. Moreno.

López, J. I. (2001). Adiós al discurso moderno en el Perú. Hueso Húmero, 39, 47-57.

López, J. I. (2002). Apuntes para la historia de la formación técnica en el Perú. En Sobre el Perú. Homenaje a José Agustín de la Puente Candamo (Tomo II, pp. 769-790). Lima, Perú: Fondo Editorial PUCP.

López, J. I. (2003). Breve Historia de la UNI. Lima, Perú: Universidad Nacional de Ingeniería.

López, J. I. \& Ludeña, W. (2000). La racionalidad ingeniero arquitectural. En Construyendo el Perú. Aportes de ingenieros y arquitectos (pp. 223-231). Lima, Perú: Proyecto de Historia UNI.

Loredo, G. \& Sánchez, N. (1904). Informe presentado al Ministerio de Fomento y a las Beneficencia de Lima y Callao por la Junta Económica del Hospicio de Insanos de la Magdalena. En Memoria administrativa que presenta a la Sociedad de Beneficencia Pública de Lima su director Don Domingo Olavegoya correspondiente al año de 1903 (pp. 418-422). Lima, Perú: Imprenta E. Moreno.

Montoya, P. (2003). Javier Prado y el positivismo peruano [Tesis de licenciatura]. Universidad Nacional Mayor de San Marcos, Lima, Perú. 
devenir Vol. 5, Nº10, JULIO - DICIEMBRE 2018, PP. 65-90 - EstudIOS I ISSN 2312-7562 | E-ISSN 2616-4949

UNIVERSIDAD NACIONAL DE INGEEIERÍA, LIMA

DOI: https://doi.org/10.21754/devenir.v5i10.599

Muñiz, M. A. (1897a). Asistencia Pública de los Enajenados. Concurso para la Construcción de un Manicomio. Lima, Perú: Imprenta La Industria.

Muñiz, M. A. (1897b). Asistencia Pública de lo Enajenados. Concurso para la Construcción de un Manicomio. Planos y croquis. Lima, Perú: Imprenta La Industria

Muñoz, F. (2001). Diversiones públicas en Lima: 1890-1920, la experiencia de la modernidad. Lima, Perú: Universidad del Pacífico.

Olavegoya, D. (1900). Hospicios de Insanos. Memoria del señor inspector. En Memoria administrativa que presenta a la Sociedad de Beneficencia Pública de Lima el primer vice director encargado de la dirección D. Pedro Gallagher correspondiente al año de 1900 (pp. 166-178.). Lima, Perú: Tomas Aguirre.

Olavegoya, D. (1902). Memoria administrativa que presenta a la Sociedad de Beneficencia Pública de Lima su director Don Domingo Olavegoya correspondiente al año de 1902. Lima, Perú: Imprenta Liberal.

Olavegoya, D. (1904). Memoria administrativa que presenta a la Sociedad de Beneficencia Pública de Lima su director Don Domingo Olavegoya correspondiente al año de 1903. Lima, Perú: Imprenta E. Moreno.

Paz Soldán, C. (1886). Estudios espiritistas y la vida de loco. Lima, Perú: Imprenta Liberal.

Ríos, A. (2013). La locura durante la Revolución mexicana. Los primeros años del Manicomio General La Castañeda, 1910-1920. México D. F.: El Colegio de México.

Ruiz, A. (1994). Psiquiatras y locos. Lima, Perú: Instituto Pasado \& Presente.

Salazar Bondy, A. (1967). Historia de las ideas en el Perú contemporáneo (Tomo I). Lima, Perú: Moncloa.

Sobrevilla, D. (1980). Las ideas en el Perú contemporáneo. En Historia del Perú (Tomo XI, pp. 113414). Lima, Perú: Mejía Baca.

Sociedad de Beneficencia Pública de Lima. (1920). Asilo Colonia de Magdalena. Lima, Perú: M. Moral.

Sociedad de Beneficencia Pública de Lima. (1913). Álbum fotográfico de los establecimientos de su cargo. Lima, Perú: M. Moral.

Sosa, B.; Loredo, G.; Romero, R.; \& Castañón, J. (1905). Nuevo informe reformatorio del anterior. En Memoria administrativa que presenta a la Sociedad de Beneficencia Pública de Lima su director D. Enrique Barreda correspondiente al año de 1904 (pp. 458-463). Lima, Perú: Tipografía Calle de la Pescadería.

Terry, T. (1901a). Cesión graciosa de un terreno. En Memoria administrativa que presenta a la Sociedad de Beneficencia Pública de Lima su director Don Pedro Gallagher correspondiente al año de 1901 (pp. 306-307). Lima, Perú: Imprenta Liberal.

Terry, T. (1901b). S/T. En Memoria administrativa que presenta a la Sociedad de Beneficencia Pública de Lima su director Don Pedro Gallagher correspondiente al año de 1901 (pp. 299-300). Lima, Perú: Imprenta Liberal.

Tovar, A. (1901). Nuevo Hospital de insanos. Resolución suprema sobre su ubicación. En Memoria administrativa que presenta a la Sociedad de Beneficencia Pública de Lima su director Don Pedro Gallagher correspondiente al año de 1901 (pp. 297-298). Lima, Perú: Imprenta Liberal.

Tovar, A. (1910). Memoria administrativa que presenta a la Sociedad de Beneficencia de Lima su director Señor Don Agustín Tovar correspondiente al año 1909. Lima, Perú: Imprenta de El Lucero.

Traslación de locos por las calles de Lima. Del Cercado a la Magdalena (16 de enero de 1918). La Prensa, 3.

Quiñones, L. (2014). Construir y modernizar: El Ministerio de Fomento (1896-1930). Lima, Perú: Centro de Historia UNI.

Valdivia, O. (1991). Panoramas de la psiquiatría en el Perú (Vol. 2). Lima, Perú: Universidad Nacional Mayor de San Marcos. 